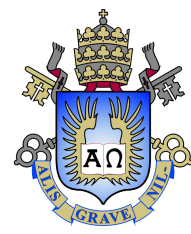

Luiz Fernando Trindade Santos

\title{
Detector de assinaturas de gás em levantamentos sísmicos utilizando LSTM
}

Dissertação apresentada como requisito parcial para a obtenção do grau de Mestre pelo Programa de Pósgraduação em Informática da PUC-Rio .

Orientador: Prof. Marcelo Gattass 
Luiz Fernando Trindade Santos Detector de assinaturas de gás em
levantamentos sísmicos utilizando LSTM

Dissertação apresentada como requisito parcial para a obtenção do grau de Mestre pelo Programa de Pósgraduação em Informática da PUC-Rio . Aprovada pela Comissão Examinadora abaixo.

Prof. Marcelo Gattass

Orientador

Departamento de Informática - PUC-Rio

Prof. Waldemar Celes Filho Departamento de Informática - PUC-Rio

Prof. Aristófanes Correa Silva

Departamento de Engenharia Elétrica - UFMA

Prof. Anselmo Antunes Montenegro Instituto de Computação - UFF 
Todos os direitos reservados. É proibida a reprodução total ou parcial do trabalho sem autorização da universidade, do autor e do orientador.

\section{Luiz Fernando Trindade Santos}

Graduado em Engenharia da Computação pela IPRJ-UERJ em 2017.

Ficha Catalográfica

Trindade Santos, Luiz Fernando

Detector de assinaturas de gás em levantamentos sísmicos utilizando LSTM / Luiz Fernando Trindade Santos; orientador: Marcelo Gattass. - Rio de janeiro: PUCRio , Departamento de Informática, 2019.

v., 56 f: il. color. ; $30 \mathrm{~cm}$

Dissertação (mestrado) - Pontifícia Universidade Católica do Rio de Janeiro, Departamento de Informática.

Inclui bibliografia

1. Informática - Teses. 2. Redes Neurais Recorrentes;. 3. Sísmica;. 4. Indicadores de Gás.. I. Gattass, Marcelo. II. Pontifícia Universidade Católica do Rio de Janeiro. Departamento de Informática. III. Título. 


\section{Agradecimentos}

Agradeço a minha família e amigos pelo suporte e ao meu orientador por toda a atenção e dedicação ao longo de toda a jornada. O presente trabalho foi realizado com apoio da Coordenação de Aperfeiçoamento de Pessoal de Nível Superior Brasil (CAPES) - Código de Financiamento 001. 


\section{Resumo}

Trindade Santos, Luiz Fernando; Gattass, Marcelo. Detector de assinaturas de gás em levantamentos sísmicos utilizando LSTM. Rio de Janeiro, 2019. 56p. Dissertação de Mestrado - Departamento de Informática, Pontifícia Universidade Católica do Rio de Janeiro.

Detectar reservatórios de hidrocarbonetos a partir de um levantamento sísmico é uma tarefa complexa, que requer profissionais especializados e muito tempo de trabalho. Por isso, atualmente, existem muitas pesquisas que buscam automatizar essa tarefa utilizando redes neurais profundas. Seguindo o sucesso das redes convolucionais profundas, CNNs, na identificação de objetos em imagens e vídeos, as CNNs tem sido utilizadas como detectores de eventos geológicos nas imagens sísmica. O treinamento de uma rede neural profunda atual, entretanto, requer centenas de milhares de dados rotulados. Se tratarmos os dados sísmicos como imagens, os reservatórios de hidrocarbonetos geralmente constituem uma pequena sub imagem incapaz de fornecer tantas amostras. A metodologia proposta nesta dissertação trata o dado sísmico como um conjunto de traços e a amostra que alimenta a rede neural são trechos de um sinal unidimensional parecido com um sinal de som ou voz. Com essa entrada uma marcação de um reservatório numa sísmica geralmente já fornece o número necessário de amostras rotuladas para o treinamento. Um outro aspecto importante da nossa proposta é a utilização de uma rede neural recorrente. A influencia de um reservatório de hidrocarboneto num traço sísmico se dá não somente no local onde ele se encontra, mas em todo o traço que se segue. Por isso propomos a utilização de uma rede do tipo longa memória de curto prazo (Long Short-Term Memory, LSTM) para caracterizar regiões que apresentem assinaturas de gás em imagens sísmicas. Esta dissertação detalha ainda a implementação da metodologia proposta e os testes feitos nos dados sísmicos públicos Netherlands F3-Block. Os resultados alcançados avaliados pelos índices de sensibilidade, especificidade, acurácia e AUC foram todos excelentes, acima de $95 \%$.

\section{Palavras-chave}

Redes Neurais Recorrentes; Sísmica; Indicadores de Gás. 


\section{Abstract}

Trindade Santos, Luiz Fernando; Gattass, Marcelo (Advisor). Direct Hydrocarbon Indicators based on LSTM. Rio de Janeiro, 2019. 56p. Dissertação de Mestrado - Departamento de Informática, Pontifícia Universidade Católica do Rio de Janeiro.

Detecting hydrocarbon reservoirs from a seismic survey is a complex task, requiring specialized professionals and long time. Consequently, many authors today seek to automate this task by using deep neural networks. Following the success of deep convolutional networks, CNNs, in the identification of objects in images and videos, CNNs have been used as detectors of geological events in seismic images. Training a deep neural network, however, requires hundreds of thousands of labeled data, that is, samples that we know the response that the network must provide. If we treat seismic data as images, the hydrocarbon reservoirs usually constitute a small sub-image unable to provide so many samples. The methodology proposed in this dissertation treats the seismic data as a set of traces and the sample that feeds the neural network are fragments of a onedimensional signal resembling a sound or voice signal. A labeled reservoir seismic image usually provides the required number of labeled one-dimensional samples for training. Another important aspect of our proposal is the use of a recurrent neural network. The influence of a hydrocarbon reservoir on a seismic trace occurs not only in its location but throughout the trace that follows. For this reason, we propose the use of a Long Short-Term Memory, LSTM, network to characterize regions that present gas signatures in seismic images. This dissertation further details the implementation of the proposed methodology and test results on the Netherlands F3-Block public seismic data. The results on this data set, evaluated by sensitivity, specificity, accuracy and AUC indexes, are all excellent, above $95 \%$.

\section{Keywords}

Recurent Neural Network; Seismic; Gas indicators. 


\section{Sumário}

1 Introdução 12

2 Trabalhos Anteriores $\quad 14$

2.1 Uso de Redes Neurais em Dados Sísmicos 14

2.2 Uso de Redes Neurais Recorrentes 16

3 Redes Longa Memória de Curto Prazo, LSTM 18

$\begin{array}{ll}3.1 \text { Redes Neurais Recorrentes } & 18\end{array}$

3.1.1 Limitações das redes recorrentes tradicionais 20

3.1.2 Longa Memória de Curto Prazo, LSTM 21

$\begin{array}{lll}3.2 & \text { Métricas de Validação } & 27\end{array}$

4 Metodologia Proposta $\quad 29$

4.1 Dimensionalidade da Solução Proposta 29

4.2 Etapas da Solução $\quad 30$

$\begin{array}{lll}4.3 & \text { Processo de Janelamento } & 31\end{array}$

4.4 Arquitetura LSTM Proposta $\quad 32$

5 Resultados $\quad \mathbf{3 4}$

5.1 Implementação 34

5.2 F3-Block 3D 35

5.3 Descrição da Base de Dados 36

5.3.1 Treinamento e Teste 37

$\begin{array}{lll}5.4 & \text { Comentários } & 37\end{array}$

5.5 Visualização 39

6 Conclusões e Trabalhos Futuros $\quad \mathbf{4 2}$

7 Referências bibliográficas $\quad 43$

A O Dado Sísmico $\quad 48$

A.1 Aquisição de Dados $\quad 52$

A.2 Processamento Sísmico $\quad 53$

A.2.1 Deconvolução $\quad 53$

A.2.2 Empilhamento $\quad 54$

$\begin{array}{ll}\text { A.2.3 Migração } & 55\end{array}$ 


\section{Lista de figuras}

Figura 3.1 Rede Neural Recorrente vs. Rede Neural Feed Forward 19

Figura 3.2 Uma rede neural recorrente desenrolada. 19

Figura 3.3 Uso de informações anteriores com pequeno intervalo de tempo. 20

Figura 3.4 Uso de informações anteriores com grande intervalo de tempo. 20

Figura 3.5 O módulo de repetição em um RNN padrão contém uma única

camada. $\quad 22$

Figura 3.6 O módulo de repetição em um LSTM contendo quatro camadas de interação.

$\begin{array}{lll}\text { Figura 3.7 Cálculo da forget gate. } & 23\end{array}$

$\begin{array}{lll}\text { Figura 3.8 Cálculo da input gate. } & 24\end{array}$

Figura 3.9 Cálculo do estado da célula de ativação. 25

$\begin{array}{ll}\text { Figura 3.10 Cálculo da saída. } & 26\end{array}$

$\begin{array}{lll}\text { Figura 4.1 Processo de Janelamento. } & 32\end{array}$

$\begin{array}{lll}\text { Figura 4.2 Arquitetura LSTM proposta. } & 33\end{array}$

Figura 5.1 ROI processo de recorte: 1 - Dado disponível (a) Cubo Sísmico F3 (b) Cubo de impedância; 2 - Área selecionada e recorte; 3 - ROI do cubo. 36

Figura 5.2 Resultado da predição do modelo para inline 249.

Figura 5.3 Resultado da predição do modelo para inline 120.

Figura 5.4 Resultado da predição do modelo para crossline 1156.

Figura 5.5 Resultado da predição do modelo para crossline 846. 41

Figura A.1 Processo de formação de um traço sísmico através da convolução do pulso emitido pela fonte com a função refletividade (FR). 50

Figura A.2 Princípio da aquisição terrestre e marítima de dados sísmicos. 52

Figura A.3 Criação dos dados sísmicos. 56 


\section{Lista de tabelas}

Tabela 5.1 Número de Janelas por Base de Dados 37

Tabela 5.2 Métricas da Base de Validação 37

Tabela 5.3 Métricas da Base de Teste 37

Tabela 5.4 Tempo Computacional em GPU 38 


\section{Lista de algoritmos}

Algoritmo 1 Processo de Janelamento 


\section{Lista de símbolos}

ADI - Análise Digital de Imagens

BIF - Banded Iron Formation

O\&G - Óleo e Gás

DNN - Deep Neural Network

NLP - Natural Language Processing

LSTM - Long short-term Memory

RNN - Recurrent Neural Network

CNN - Convolutional Neural Network

SVM - Support Vector Machine

MLP - Multilayer Perceptron

ICDAR - International Conference on Document Analysis and Recognition

ROI - Region of Interesting

AUC - Area Under Roc Curve

DHI - Direct Hydrocarbon Indicators

SEG - Society of Exploration

CMP - Common Mid-Point

DMO - Dip Move-Out

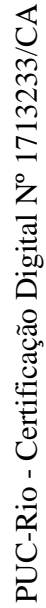

CRP - Common Reflection Point 


\section{1 \\ Introdução}

A sísmica de reflexão é um dos métodos geofísicos mais empregados pela indústria de óleo de gás $(\mathrm{O} \& \mathrm{G})$. O levantamento sísmico fornece informações significativas sobre a geometria das camadas e a configuração estrutural em subsuperfície. Utilizado em conjunto conhecimentos sobre a geologia local, com outros dados geofísicos e algoritmos computacionais, a sísmica nos permite obter indicações sobre o tipo de rocha, litologia, e suas propriedades físicas. Com base nessas informações um geocientista pode inferir a localização e volume de possíveis acúmulos de hidrocarbonetos.

Para a interpretação das informações fornecidas o estudo da sísmica de reflexão, foca em dois aspectos fundamentais do sinal: tempo de chegada e forma da onda. O tempo de chegada das ondas refletidas em contatos de camadas da subsuperfície com propriedades físicas distintas se relaciona com a profundidade dessas interfaces geológicas. A forma, a intensidade, o espectro de frequência e a distribuição dessas frequências longo de duração do traço sísmico revelam o tipo de rocha de cada camada (litologia) e as propriedades físicas delas (1).

Ocorre, entretanto, que assim como os demais métodos geofísicos, a sísmica de reflexão gera dados ambíguos (2). No procedimento de interpretação sísmica, os geocientistas escolhem um modelo geológico final a partir de uma gama de possíveis cenários que os dados permitem. Isto torna a interpretação uma atividade que demanda muito tempo de equipes especializadas. Esse tempo, entretanto, nem sempre é compatível com os curtos prazos exigidos pela indústria e o volume de dados sísmicos a ser analisado.

Áreas que apresentam problemas similares ao da interpretação geofísica, grande volume de dados, prazos curtos e intenso esforço humano, estão atualmente fazendo uso de de redes neurais profundas, Deep Neural Networks, como solução. A cada ano as redes neurais profundas estão produzindo eficientemente resultados cada vez mais confiáveis. Exemplos dessas áreas de sucesso das redes são processamento de linguagem natural (NLP) (3), processamento de imagem (4), e processamento de sinais (5).

O uso de redes neurais profundas em geofísica, entretanto, apresenta uma dificuldade que não existe nas áreas citadas acima. $\mathrm{O}$ treinamento delas é bastante dificultado pela pouca quantidade de dados rotulados. O treinamento de Redes Neurais Convolucionais para detectar assinaturas de gás, por exemplo, requer muitos retalhos (patches) da imagem sísmica rotulados como sendo regiões de gás ou não. Essa informação, entretanto, não está disponível na maioria dos levantamentos. Para con- 
tornar essa situação a linha de pesquisa na qual essa dissertação está inserida tem tentado fazer o treinando das redes Convolucionais para detectar falhas, utilizando dados sísmicos sintéticos. Recentemente Axelle (6) propôs utilizar uma técnica de transferência de conhecimento, transfer learning, para adaptar uma CNN treinada em dados sintéticos para dados reais.

A geração de dados sintéticos que simulem falhas e horizontes é simples, mas gerar dados sísmicos que representem a assinatura de reservatório de gás é bem mais complicado. Por isso, neste trabalho optou-se por buscar uma maneira de aumentar o número de amostras rotuladas em dados sísmicos, mesmo com a identificação de pequenas regiões de reservatórios. Isto foi obtido abandonando a ideia de que um retalho de imagem é a amostra que deve gerar o vetor de característica da rede neural. Nesta dissertação propomos a utilização de trechos dos traços sísmicos como vetores característicos. Os trechos em que o traço atravessa a camada de sal geram o vetor de amostras rotuladas como assinaturas de gás. Mais ainda, como a presença do sal afeta todo o traço, não somente a região do reservatório, propomos a utilização de uma rede recorrente para levar em conta essa influencia acumulada.

O objetivo desta dissertação é propor e avaliar um modelo de rede neural recorrente do tipo longa memória de curto prazo (Long Short-Term Memory, LSTM) para caracterizar regiões que apresentem assinaturas de gás em imagens sísmicas. Para treinar e avaliar a rede utilizamos o conjunto de dados sísmicos públicos Netherlands F3-Block [OSR].

A dissertação deu origem a um artigo aceito na Sociedade de Geofísicos de Exploração (SEG), um pedido de patente em processo na PUC-Rio e um projeto de pesquisa com uma empresa de $\mathrm{O} \& \mathrm{G}$.

Esse documento esta estruturado da seguinte forma. O capítulo 3 trás alguns fundamentos para melhor entendimento desse trabalho. No capítulo 4 é apresentado o método proposto. O capítulo 5 mostra os resultados encontrados. Finalmente no capítulo 6 são apresentados a conclusão e os trabalhos futuros. 


\section{2}

\section{Trabalhos Anteriores}

Como não encontramos nenhum trabalho anterior que tratasse do uso de redes neurais recorrentes em dados sísmicos e nem nenhuma abordagem para a detecção de hidrocarbonetos, dividimos este capítulo em duas seções. A primeira revisa o uso das redes neurais em dados sísmicos de reflexão e a segunda o uso de redes recorrentes com enfase na LSTM.

\section{1}

\section{Uso de Redes Neurais em Dados Sísmicos}

Uma das principais abordagens que vem sendo empregadas em dados sísmicos é combinar atributos usando algoritmos de aprendizado de máquina. Os métodos supervisionados se baseiam em um conjunto de entradas rotuladas e, em seguida, aplicam o conhecimento adquirido para prever novas amostras. Os vetores de características nesses casos, são vetores com os valores dos atributos sísmicos e os rótulos são a classificação dos voxels como falhas ou horizontes. Por exemplo, Tingdahl e De Rooij (7) usaram um conjunto de 12 atributos como entrada de uma Rede Neural MLP, gerando mapas de probabilidade de falha. As Máquinas de Vetores de Suporte (SVMs, do inglês Support Vector Machines) também obtiveram resultados promissores quando usado com uma seleção de atributos sísmicos (8), ou texturas de imagem (9), e atributos sísmicos em dados de pré-stack (10).

$\mathrm{O}$ recente aumento no poder computacional permitiu o uso de técnicas de aprendizagem profunda. Em comparação com os métodos padrão de aprendizado de máquina, as redes profundas podem aprender novos atributos dinamicamente durante o treinamento, explicando seu sucesso na solução de tarefas complexas. Araya-Polo et al. (11) treinaram redes neurais profundas em dados sintéticos préempilhados e detectaram falhas introduzindo função de perda de Wasserstein. Métodos orientados a imagem, como as Redes Neurais por Convolução (Convolucional Neural Networks-CNNs), são especialmente promissores, uma vez que recentemente alcançaram resultados significativos (12). Enquanto (13) usaram CNNs em mapas de atributos sísmicos, (14) e (15) mostraram que tais redes poderiam funcionar bem diretamente com a amplitude sísmica como a única entrada, evitando a computação de vários atributos, computacionalmente caros.

O trabalho de Chevitarese et al. (17) que aborda a classificação de fácies sísmicas, identificação da representação de cada camada do registro sísmico, usando CNNs. Os autores apresentam uma metodologia para processar e organizar dados sísmicos pós-stack em pequenas partições (patches) para torná-los compatíveis com 
datasets para treino e teste em uma rede profunda, seguidamente aplicando-os na rede para classificação. Para tal metodologia, os mesmos usam dois dados públicos Penobscot-3D e Netherlands F3-Block [OSR]. Posteriormente, em Chevitarese et al. (18), é apresentado um procedimento para transferência de aprendizado (transfer-learning) aplicado ao mesmo problema supracitado. Ainda usando os mesmos dados públicos do trabalho anterior, os autores aplicam os parâmetros aprendidos por uma rede CNN treinada em um determinado cubo sísmico e usam como parâmetros iniciais para a criação do modelo de classificação de um outro dado sísmico com geologia distinta.

Em contrapartida a classificação de fácies sísmicas usando a metodologia de divisão das imagens sísmicas em pequenos patches para CNN, Zhao (19) apresenta uma outra vertente. $\mathrm{O}$ autor expõe uma alternativa ao procedimento supracitado usando modelos CNN desenvolvidos para segmentação de imagens, obtendo assim as classificações em perfis 2D (inline x crossline) na escala da amostra do sinal. O próprio também usa a metodologia "tradicional" de divisão em patches para comparação.

Ma et al. (20) apresentam uma metodologia também usando CNN para gerar um atributo sísmico que evidencia as falhas. $\mathrm{O}$ trabalho denota o uso de 7 cubos sísmicos diferentes, amostrados em voxels para uma abordagem de treinamento supervisionado. Para critérios de teste e avaliação do modelo treinado, os autores aplicam rede tanto em dados sísmicos sintéticos (gerados a partir de um modelo sintético da Terra), quanto em dados sísmicos reais. Uma abordagem similar é apresentada por Araya-Polo et al. (11). O trabalho também objetiva a detecção automática de falhas utilizando redes neurais profundas, todavia o mesmo apresenta uma metodologia com enfoque maior em dados sintéticos pré-empilhamento (prestack) e no aperfeiçoamento de modelos de velocidade para migração sísmica.

Outro levantamento sísmico que apresenta grande desafio para os intérpretes identificarem e delinearem é o referente a domos de sal. Particularmente difíceis de se imagear, obter-se sinais reflexivos oriundos desse tipo de corpo, devido a alta variação lateral de velocidade de propagação da onda e alto contraste de impedância acústica, as camadas de evaporitos (rochas salinas) deformadas podem mascarar grande parte dos refletores laterais e abaixo no registro sísmico, que podem ser potenciais locais de acúmulo de hidrocarbonetos.

Os trabalhos de Di, Whang e AlRegib (22) apresentam como solução para detecção de sal o uso de deep learning. No primeiro trabalho, os autores aplicam uma CNN para o delineamento automático de domos de sais em um dataset real. Para critérios de comparação, além do resultado da interpretação manual, o trabalho exibe também os resultados aplicando técnicas de aprendizados de máquina tradicional, o support-vector machine (SVM) e uma rede multi-layer 
perceptron (MLP). No segundo trabalho, os mesmos apresentam uma comparação entre a aplicação de MLP e de CNN para interpretação sísmica, focando no caso de delimitação de domos de sais e mapeamento de falhas. Os autores concluem que a abordagem utilizando a técnica de deep learning é mais vantajosa devido a geração automática de uma biblioteca de atributos oriunda das camadas convolucionais e o uso de pequenos patches para a etapa de classificação, levando em consideração padrões locais no sinal sísmico.

No problema estudado nesta dissertação a geração de dados sintéticos para obter o número necessário de amostras rotuladas para o treinamento da rede neural profunda, é bastante difícil. Por isso nenhuma das estratégias já existentes é capaz de resolver o problema de detecção de reservatórios de gás.

\section{2}

\section{Uso de Redes Neurais Recorrentes}

O modelo de redes neurais recorrentes (RNN, Recurrent Neural Network) dá base a um poderoso conjunto de algoritmos de aprendizado de máquina especialmente úteis para solucionar problemas que envolvam a interpretação de sinais temporais tipo som, medição de sensores, séries temporais e processamento de linguagem natural.

A primeira formulação de uma rede neural recorrente foram as redes de Hopfield descobertas por John Hopfield em 1982 (23). Ela consistia em uma única camada que continha um ou mais neurônios recorrentes totalmente conectados. Geralmente era uma rede usada para tarefas de auto-associação e otimização.

Um dos problemas encontrados em redes RNNs são as chamadas "dependências de longo prazo", que corresponde ao intervalo entre a informação relevante e o ponto que ela é usada. Na teoria, as RNNs são absolutamente capazes de lidar com elas. Porém, na prática, isso não ocorre. Esse problema foi explorado em profundidade por Bengio, et al. em 1994 (24).

Em 1997 Hochreiter e Jürgen Schmidhuber (26) introduziram as Redes de Memória de Longo Prazo (Long Short Term Memory) capazes de aprender dependências de longo prazo. As alterações feitas por eles nas redes recorrentes permitiu o LSTM contornar os problemas dos gradientes tenderem para zero ou infinito (exploding and vanishing gradient problems).

Felix Gers e seu orientador Jürgen Schmidhuber em 1999 introduziram o forget gate (também chamado de "keep gate") na arquitetura LSTM, (27) permitindo que o LSTM redefinisse seu próprio estado (28).

Entre outros sucessos, o LSTM alcançou resultados recordes em compressão de texto em linguagem natural, reconhecimento de manuscrito conectado nãosegmentado (29) e venceu o concurso de caligrafia, (ICDAR - International Con- 
ference on Document Analysis and Recognition) em 2009. As redes LSTM foram um componente importante de uma rede que atingiu uma taxa de erro de fonema recorde de 17,7\% no conjunto de dados de discurso natural TIMIT clássico em 2013 (30).

A partir de 2016, grandes empresas de tecnologia, incluindo Google, Apple e Microsoft, começaram a utilizar o LSTM como um dos componentes fundamentais em novos produtos (31). Por exemplo, o Google usou a LSTM para reconhecimento de voz no smartphone, (32) (33) para o assistente inteligente Allo (34) e para o Google Translate (35) (38). A Apple usa o LSTM para a função "Quicktype"no iPhone (36) (37) e para o Siri (39). A Amazon usa o LSTM para o Amazon Alexa (40).

Em 2017, a Microsoft atingiu 95,1\% de precisão de reconhecimento de voz no Switchboard corpus, em um vocabulário de 165.000 palavras (41). Nesse mesmo ano, pesquisadores da Michigan State University, da IBM Research e da Cornell University publicaram um estudo na conferência de Knowledge Discovery and Data Mining (KDD) (42). Este estudo descreve uma nova rede neural que funciona melhor em determinados conjuntos de dados do que a rede neural de memória de longo prazo amplamente utilizada. Entretanto ainda é cedo para avaliarmos essa nova rede em aplicações no setor de petróleo e gás. 


\section{3 \\ Redes Longa Memória de Curto Prazo, LSTM}

Os conceitos sobre redes neurais recorrentes apresentados neste capítulo focam nas redes do tipo longa memória de curto prazo (Long Short-Term Memory, LSTM), que estão na base da metodologia proposta nesta dissertação. No final do capítulo também são apresentadas as métricas clássicas de validação de redes neurais que são utilizadas na avaliação do método proposto: sensibilidade, especificidade, acurácia e AUC. O leitor que já conheça a LSTM e esses conceitos pode seguir diretamente para o próximo capítulo.

\section{1 \\ Redes Neurais Recorrentes}

Redes neurais tradicionais, tais como a perceptron multicamadas (Multi Layer Perceptron, MLP), não apresentam ciclos em sua estrutura, ou seja, não possuem retro alimentação. A informação nestas redes só se propaga em uma direção e por isso elas são também conhecidas como feedforward. A informação entra na camada de entrada e passa pelas camadas escondidas até atingir a camada de saída. Ou seja, nas redes feedforward um dado vetor de entrada produz um único vetor de saída, independentemente do contexto em que a entrada ocorreu.

A ideia principal por trás de um modelo de rede neural recorrente é fazer uso do contexto em informações sequenciais. Isto é importante para algumas tarefas, como previsão de séries temporais ou reconhecimento de fala, onde uma informação isolada não faz sentido. Para o caso em que se quer prever, por exemplo, a próxima palavra em uma frase, é imprescindível saber quais palavras vieram antes dela. Esse modelo de rede é chamado de recorrente pois executam a mesma tarefa para cada elemento de uma sequência, com a saída sendo dependente dos cálculos anteriores. Outra maneira de pensar sobre esse modelo de rede é que eles têm uma memória que registra o que foi calculado até agora. Em teoria, elas podem fazer uso de informações em sequências arbitrariamente longas, mas, na prática, limitam-se a olhar para trás apenas alguns passos.

Assim com outros modelos de redes neurais, as redes recorrentes são úteis para clusterização e detecção de anomalias. Ou seja, eles reconhecem semelhanças e dissimilaridades agrupando exemplos no espaço vetorial e medindo a distância entre eles.

Nos modelos de redes recorrentes o valor alcançado na etapa de tempo $t$ é diretamente influenciado pelos valores da etapa de tempo $(t-1)$. Assim, as redes recorrentes têm duas fontes de entrada, o presente e o passado recente, que se 
combinam para determinar como elas respondem. A Figura 3.1 ilustra a forma como ocorre o fluxo de informação em cada modelo.
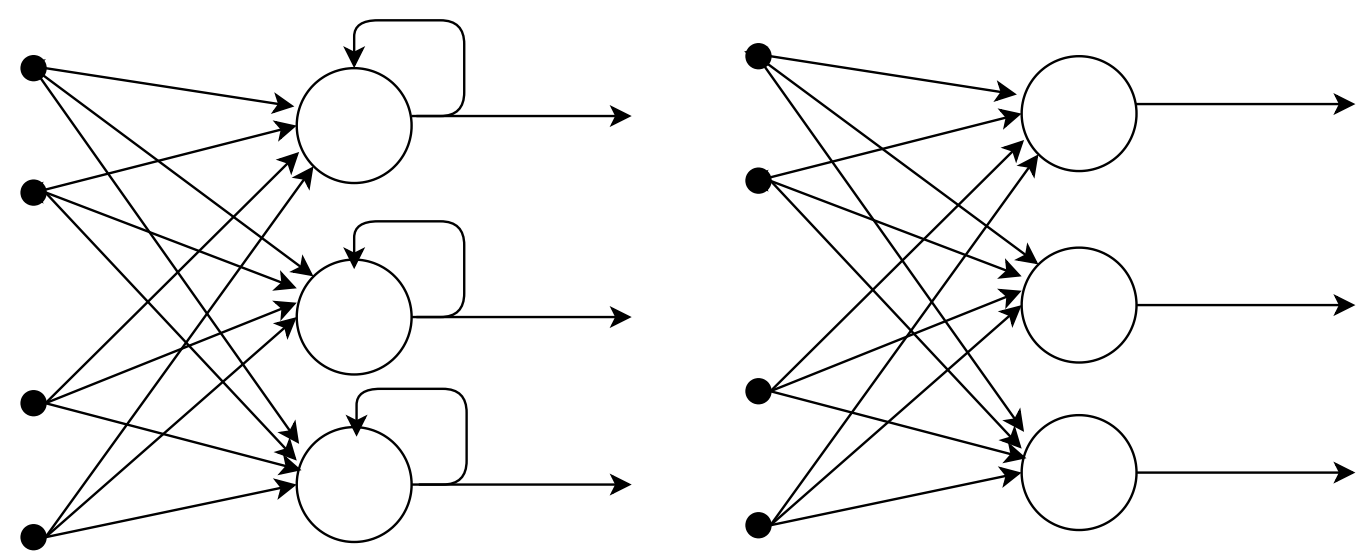

Figura 3.1: Rede Neural Recorrente vs. Rede Neural Feed Forward

Uma rede neural recorrente pode ser imaginada como múltiplas cópias da mesma rede, cada uma passando uma informação ao seu sucessor. A Figura 3.2 apresenta o loop na RNN desfeito.
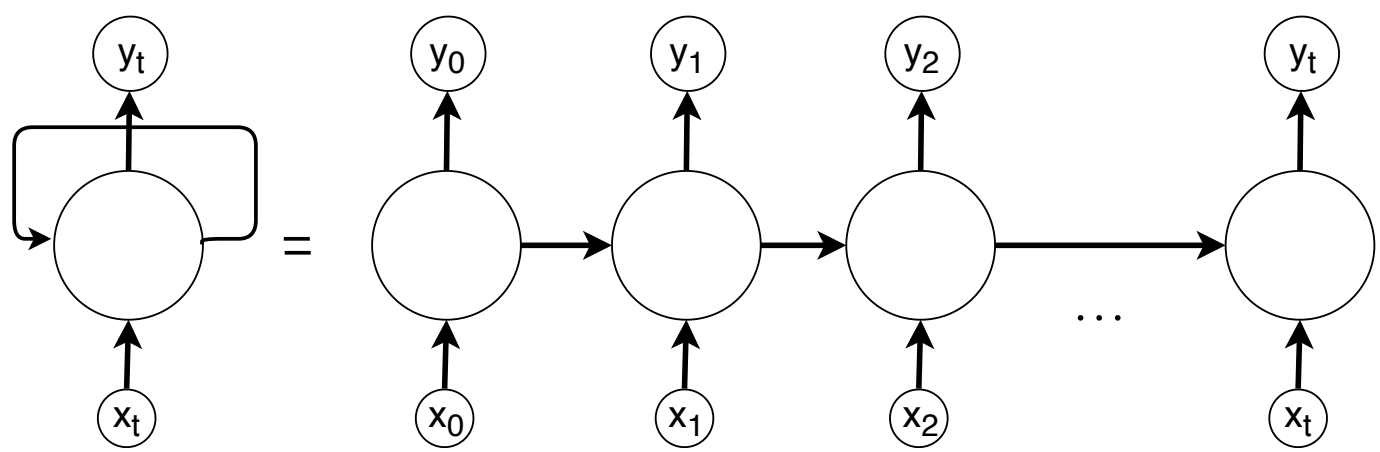

Figura 3.2: Uma rede neural recorrente desenrolada.

Essa estrutura em cadeia revela que redes neurais recorrentes estão intimamente relacionadas a sequências e listas. Sendo assim, essa arquitetura é imprescindível a ser usada para esse tipo dado.

A ideia de informação sequencial é preservada nas camadas escondidas da rede recorrente, que consegue passar muitos intervalos de tempo, à medida que a informação avança no modelo, para afetar o processamento de cada novo exemplo. Com isso o modelo consegue encontrar correlações entre eventos separados por muitos momentos, e essas correlações são chamadas de "dependências de longo prazo", pois um evento no tempo depende e é uma função de um ou mais eventos que vieram anteriormente. 


\subsection{1}

\section{Limitações das redes recorrentes tradicionais}

Um dos recursos dos modelos RNNs é a ideia de que eles podem conectar informações anteriores à tarefa atual, como, por exemplo, o uso de frames de vídeo anteriores, que podem informar o entendimento do frame atual. Contudo, esses modelos podem realizar essa tarefa com algumas limitações.

Em alguns casos, precisamos apenas examinar informações recentes para executar a tarefa atual, ou seja, onde a distância entre as informações relevantes e o local necessário é pequena. Os modelos RNNs podem aprender a usar as informações anteriores. A Figura 3.3 ilustra essa situação.

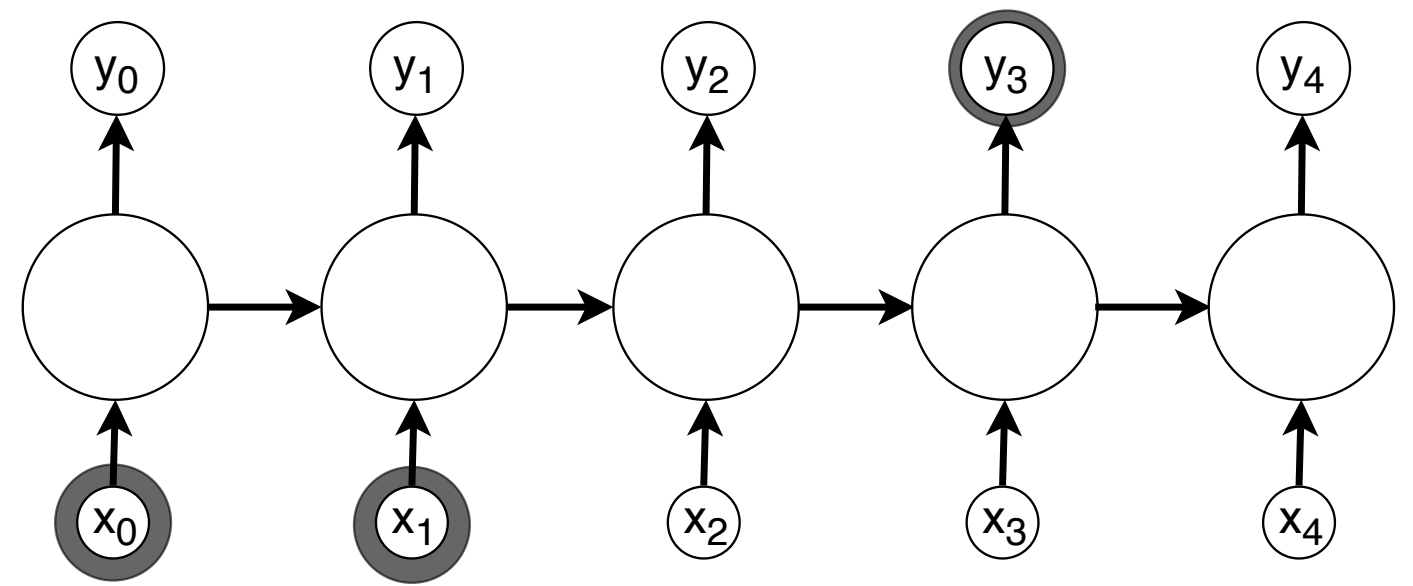

Figura 3.3: Uso de informações anteriores com pequeno intervalo de tempo.

Mas também há casos em que precisamos de mais contexto, ou seja, o intervalo entre a informação relevante e o ponto em que ela é necessária tornarse muito grande. Logo, à medida que essa distancia aumenta, as RNNs tornam-se incapazes de aprender a conectar as informações.

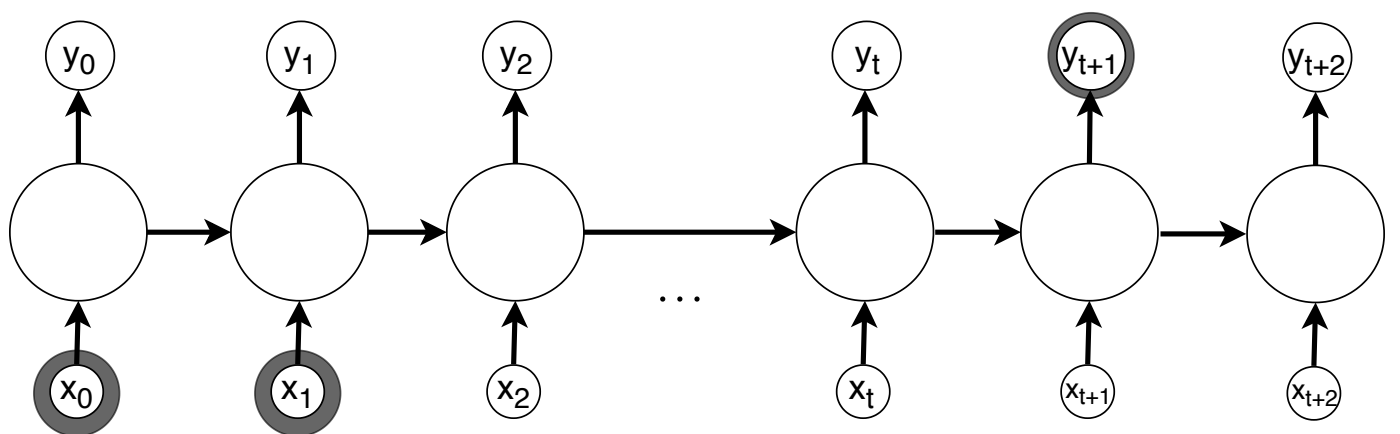

Figura 3.4: Uso de informações anteriores com grande intervalo de tempo.

Em teoria, as RNNs são absolutamente capazes de lidar com essas "dependências de longo prazo". Porém, na prática, as RNNs não parecem ser capazes de aprendê-los. Esse problema é explicado em detalhes por Hochreiter e Bengio, et al. (25). 
Além desse problema "dependências de longo prazo" a rede de recorrência padrão ainda apresenta dois grandes obstáculos: o "Exploding Gradients"e o "Vanishing Gradients". Para enteder melhor esses dois fenômenos, é preciso entender a importância do gradiente no processo.

Um gradiente corresponde a derivada parcial em relação às entradas do modelo. Ele mede o quanto a saída de uma função muda, se ocorrer uma pequena alteração das entradas. Uma forma de pensar o gradiente é correlaciona-lo a inclinação de uma função. Quanto maior o gradiente, mais íngreme a inclinação e mais rápido o modelo pode aprender. Mas se a inclinação é zero, o modelo pára de aprender, pois sem saber o gradiente, não é possível ajustar os pesos em uma direção que diminuirá o erro.

O fenômeno de "Exploding Gradients"ocorre quando o algoritmo atribui uma importância alta ao valor dos pesos. Para contornar esse problema pode ser facilmente resolvido se você truncar ou esmagar os gradientes. Em contra partida, o "Vanishing Gradients"ocorre quando os valores de um gradiente são muito pequenos e o modelo pára de aprender ou demora muito por causa disso. Este foi um grande problema nos anos 90 e muito mais difícil de resolver do que o "Exploding Gradients".

Esses dois fenômeno ocorrem parcialmente porque a informação que flui através das redes neurais passam por muitos estágios onde a saída de um é a entrada de outro. Pela regra da cadeia é possível explicar que o gradiente final é um produto das derivadas de cada estágio. Como em cada estágio a entrada é multiplicada por um fator essa derivada é o próprio fator. Se ele for menor que 1, ele elevado a uma potencia alta tente a zero. Se for maior que 1 , tende a infinito. Ou seja, as derivadas são suscetíveis a desaparecer ou explodir nas redes recorrentes.

Diversos trabalhos foram realizados nos anos 90 para tentar contornar em especial esse segundo problema. Dentre eles destacam-se: o uso de algoritmos de treinamento não baseados em gradiente, tais como simulated annealing e discrete error propagation (Bengio et al., 1994), introdução explícita de time delays (Lang et al., 1990; Lin et al., 1996; Plate, 1993) ou constantes de tempo (Mozer, 1992) e compressão de sequência hierárquica (Schmidhuber, 1992) entre outros. Neste trabalho será usada a abordagem de arquitetura LSTM (Long-Term Short Memory) (Hochreiter e Schmidhuber,1997).

\subsection{2}

\section{Longa Memória de Curto Prazo, LSTM}

A arquitetura de um modelo LSTM basicamente consiste de um conjunto de sub-redes conectadas recorrentemente, denominadas de blocos de memória. Cada bloco contém uma ou mais células de memória auto-conectadas e três unidades 
multiplicativas para proteger e controlar o estado da célula, sendo elas: as portas de entrada, saída e "forget gates", os quais realizam as operações de adição, leitura e redefinição das células.

As redes neurais recorrentes têm a forma de uma série de módulos repetitivos. Em RNNs padrão, este módulo de repetição terá uma estrutura muito simples, com a presença, por exemplo, de uma tangente hiperbólica (tanh) em sua camada escondida.

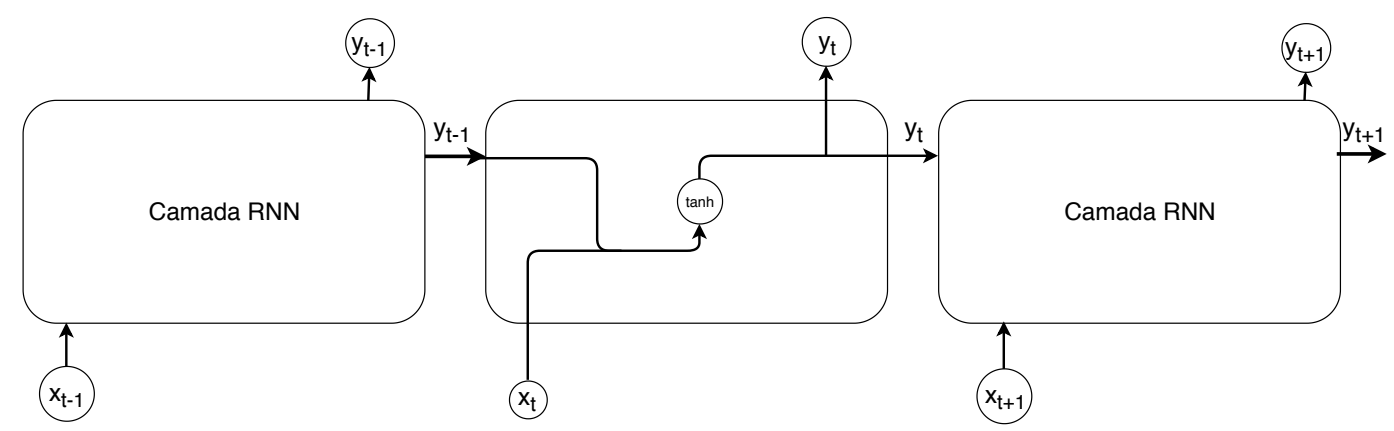

Figura 3.5: O módulo de repetição em um RNN padrão contém uma única camada.

Já as células de memória LSTMs também possuem esta estrutura em série, mas o módulo de repetição possui uma estrutura diferente. Em vez de ter uma única camada de rede neural, existem quatro, interagindo de uma maneira muito especial. A Figura 3.6 ilustra uma dessas células de memória.

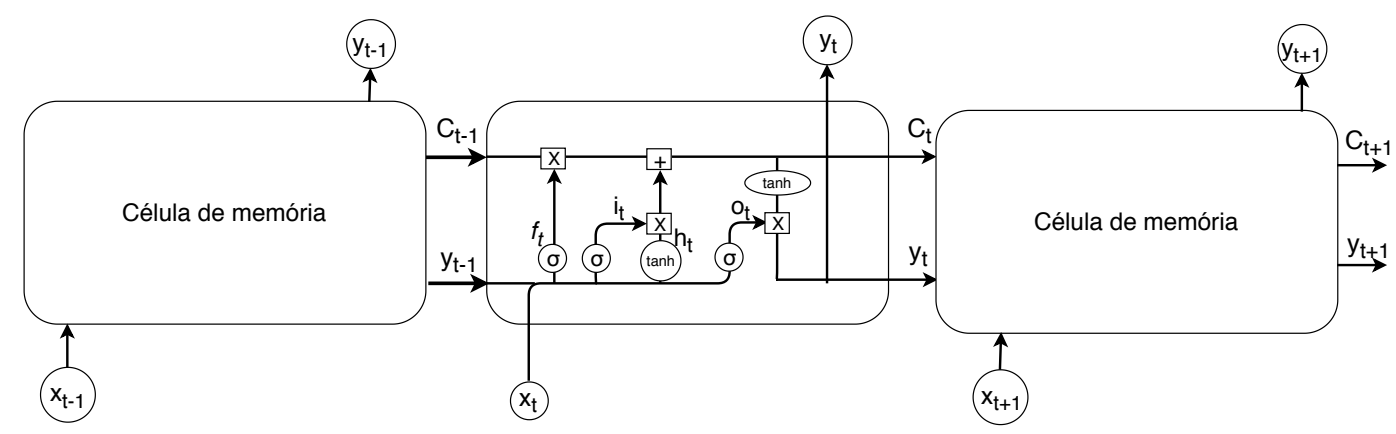

Figura 3.6: O módulo de repetição em um LSTM contendo quatro camadas de interação.

No diagrama acima, cada linha representa um vetor, desde a saída de um nó até as entradas de outros. Os quadrados representam operações elemento a elemento, como a adição de vetores, enquanto os círculos são as camadas da rede neural. As linhas que se fundem denotam a concatenação, enquanto uma linha bifurcada denota que seu conteúdo está sendo copiado e as cópias vão para locais diferentes.

A ideia central sobre as LSTMs é o estado da célula, a linha horizontal que passa pela parte superior do diagrama. O estado da célula é responsável por 
transportar a informação ao longo da célula de memória. Ele percorre toda a cadeia, com apenas algumas interações lineares menores.

As portas são uma forma de, opcionalmente, deixar passar as informações. Elas são compostas de uma camada de rede neural com a função de ativação sigmoide e uma operação de multiplicação elemento a elemento. A função sigmoide produz números entre zero e um, descrevendo quanto de cada componente deve ser liberado.

Como visto nas Figuras 3.5 e 3.6, um modelo de rede LSTM é bastante similar a um modelo RNN padrão, com exceção da substituição das camadas escondidas pelos blocos de memória. Já as camadas de saída podem ser usadas de forma similar para ambos os modelos. Assim, uma rede neural LSTM processa uma dada entrada $x=\left(x_{1}, x_{2}, \ldots, x_{n-1}, x_{n}\right)$ para uma saída $y=\left(y_{1}, y_{2}, \ldots, y_{n-1}, y_{n}\right)$ da seguinte maneira:

1. O primeiro passo na LSTM é decidir quais informações vão ser descartar do estado da célula. Esta decisão é feita por uma camada sigmoide chamada de "forget gate". Ela olha para $y_{t-1}$ e $x_{t}$ e produz um número entre 0 e 1 para cada número no estado da célula de ativação $C_{t-1}$.

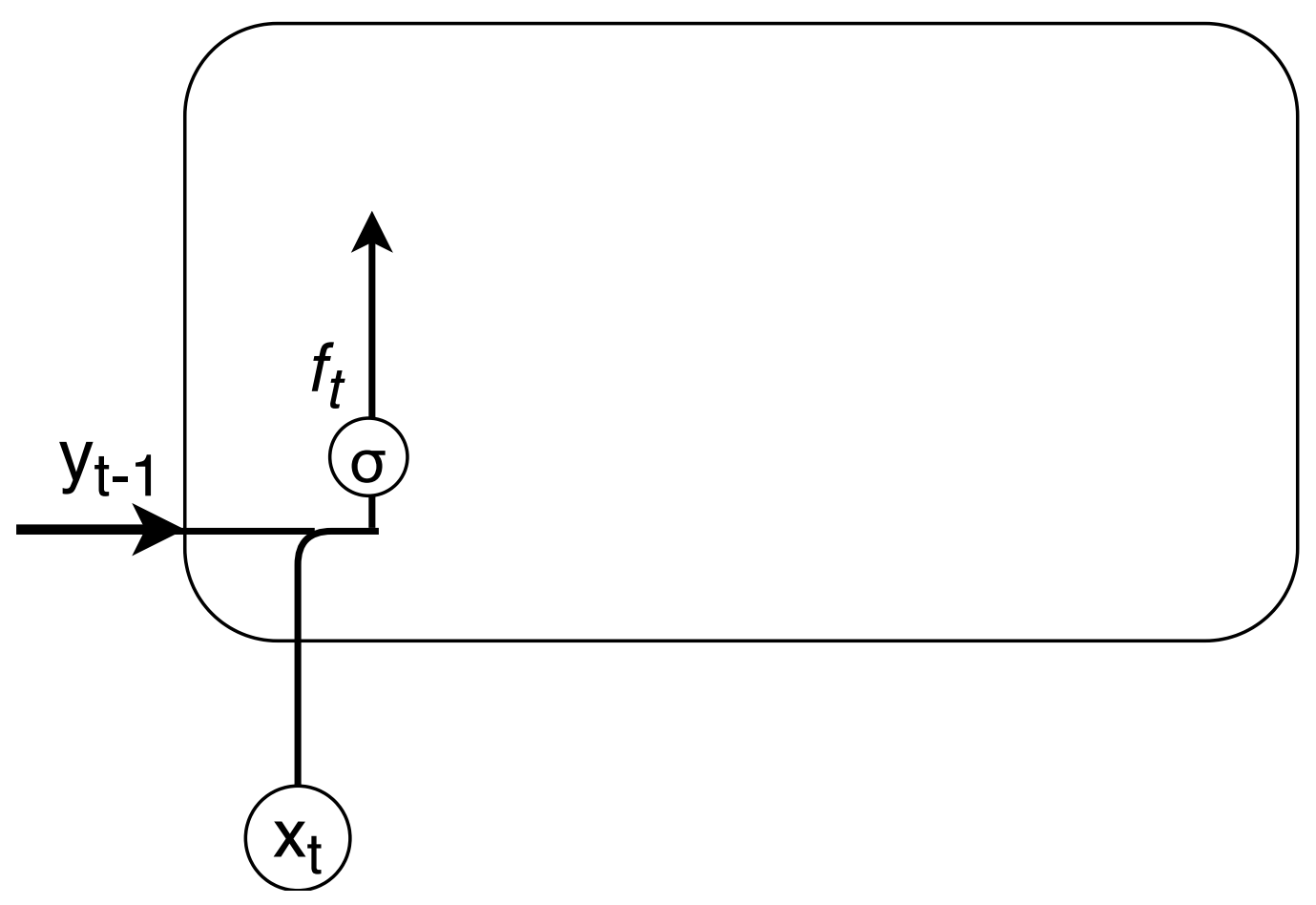

Figura 3.7: Cálculo da forget gate.

$$
f_{t}=\sigma\left(W_{f} \cdot\left[y_{t-1}, x_{t}\right]+b_{f}\right)
$$

2. O próximo passo é decidir quais novas informações serão armazenadas no estado da célula. Esse processo possui duas partes. Primeiro, uma camada 
sigmoide chamada "input gate"decide quais valores serão atualizados. Em seguida, uma camada de tanh cria um vetor de novos valores candidatos, $h_{t}$, que podem ser adicionados ao estado. Na próxima etapa, será combinado esses dois para criar uma atualização para o estado.

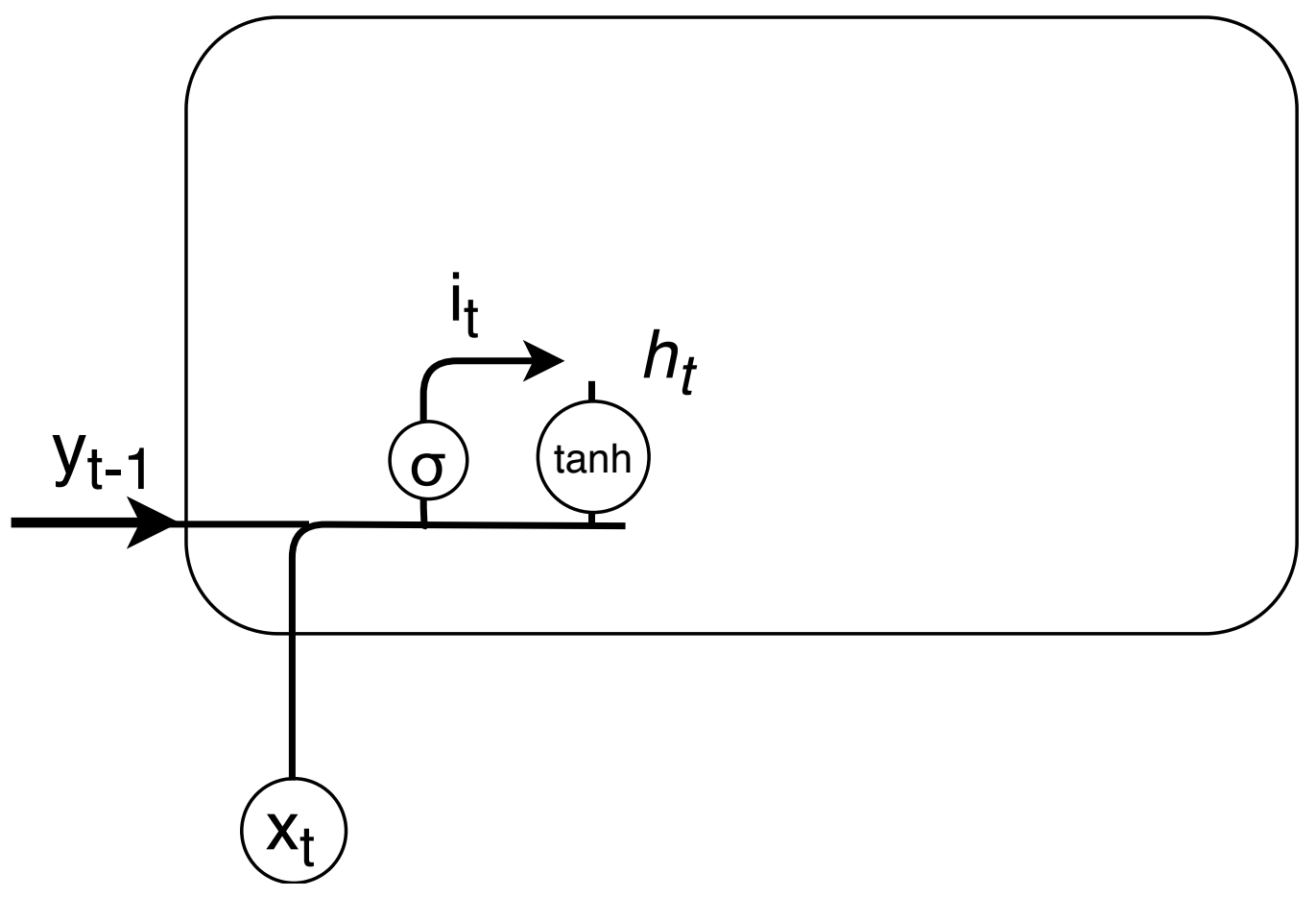

Figura 3.8: Cálculo da input gate.

$$
\begin{gathered}
i_{t}=\sigma\left(W_{i} \cdot\left[y_{t-1}, x_{t}\right]+b_{i}\right) \\
h_{t}=\tanh \left(W_{C} \cdot\left[y_{t-1}, x_{t}\right]+b_{C}\right)
\end{gathered}
$$

3. Em seguida deverá ser atualizado o estado da célula antiga, $C_{t-1}$, para o novo estado da célula $C_{t}$. Para isso, basta multiplicar o antigo estado da célula por $f_{t}$. E então adicionar $i_{t} \cdot C_{t-1}$. Esses serão os novos valores candidatos, para atualizar cada valor de estado. 


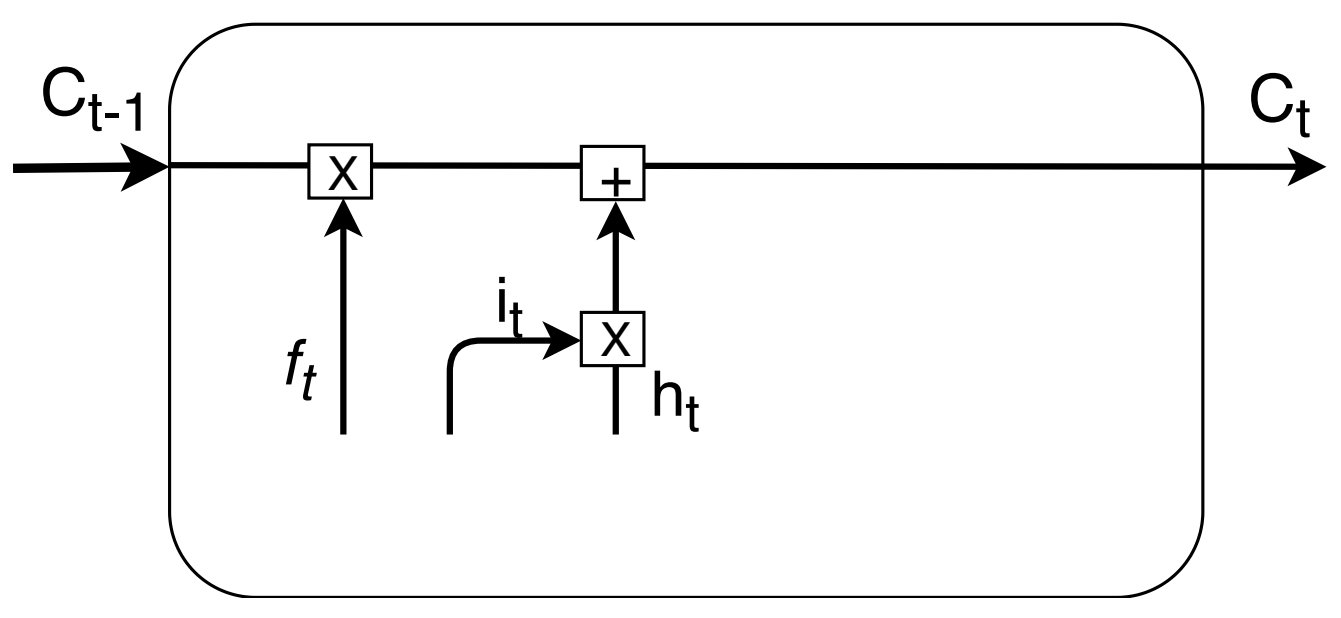

Figura 3.9: Cálculo do estado da célula de ativação.

$$
\left.C_{t}=f_{t} \odot C_{t-1}+i_{t} \odot h_{t}\right)
$$

4. Por fim, falta determinar a saída. Essa saída será baseada no estado da célula, com algumas alterações. O primeiro processo consiste por uma camada sigmoide que decide quais partes do estado da célula produzirá a saída. Em seguida, colocamos o estado da célula através de tanh. 


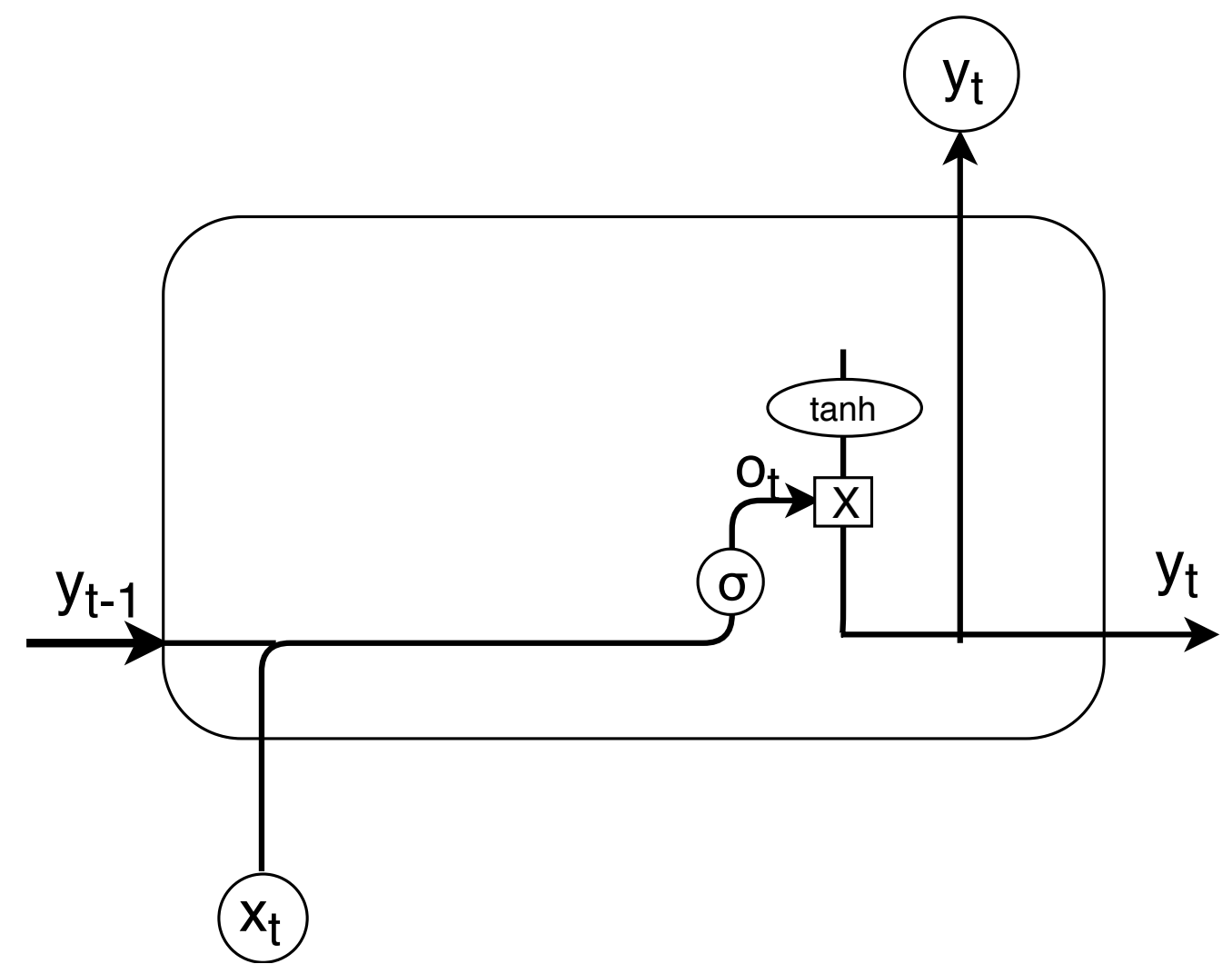

Figura 3.10: Cálculo da saída.

$$
\begin{gathered}
o_{t}=\sigma\left(W_{o} \cdot\left[y_{t-1}, x_{t}\right]+b_{o}\right) \\
y_{t}=o_{t} \odot \tanh \left(C_{t}\right)
\end{gathered}
$$

Nas equações descritas acima $\mathrm{W}$ representa as matrizes de peso, os termos $\mathrm{b}$ são os vetores de bias, $\sigma$ é a função de ativação sigmoide. i, f, o e c são os vetores de input gate, forget gate, output gate e a célula de ativação respectivamente. Todos as gates são do mesmo tamanho que o vetor de ativação de saída da célula. Por fim, $\odot$ é o produto elemento a elemento dos vetores,

As unidades multiplicativas presentes nas células de memória são responsáveis por armazenarem e acessarem as informações por longo períodos de tempo, e assim, resolvendo o vanishing gradient problem. Por exemplo, enquanto a porta de entrada permanecer fechada (ou seja, tiver uma ativação próxima a 0), a ativação da célula não será sobrescrita pelas novas entradas que chegam à rede, e pode, portanto, ser disponibilizado para a rede muito mais tarde na sequencia, abrindo o output gate. 


\section{Métricas de Validação}

Para avaliar modelos que envolvam problemas de classificação existem algumas métricas empregadas pela literatura. Através delas é possível comparar os modelos gerados a partir de diferentes algoritmos ou dos mesmos algoritmos sujeitos a diferentes parâmetros. Logo, elas são essenciais para encontrar a melhor configuração de um modelo de classificação.

Para avaliar a metodologia proposta neste trabalho foram escolhidas as seguintes métricas: sensibilidade, especificidade, acurácia e área abaixo da curva ROC. Elas apresentam as seguintes relações:

$$
\begin{gathered}
\text { sensibilidade }=\frac{T P}{T P+F N} \\
\text { especificidade }=\frac{T N}{T N+F P} \\
\text { acurácia }=\frac{T P+T N}{T P+T N+F P+F N} \\
A U C=\frac{1}{m n} \sum_{i=1}^{m} \sum_{j=1}^{n} \Gamma p_{i}>p_{j}
\end{gathered}
$$

onde,

- TP é o número de verdadeiros positivos (amostras de gás classificadas como gás),

- TN é o número de verdadeiros negativos (amostras de não gás classificadas como não gás),

- FP é o número de falsos positivos (amostras de não gás classificadas como gás) e

- FN é o número de falsos negativos (amostras de gás classificadas como não gás).

- Em relação à expressão AUC, é executado todos os m pontos de dados com o verdadeiro rótulo 1 , e $\mathrm{j}$ executa todos os $\mathrm{n}$ pontos de dados com o verdadeiro rótulo $0 ; p_{i}$ e $p_{j}$ denotam a pontuação de probabilidade atribuída pelo classificador aos pontos de dados i e j, respectivamente. $\Gamma$ é a função do indicador: gera 1 se a condição (aqui $p_{i}>p_{j}$ ) estiver satisfeita.

A sensibilidade avalia a capacidade do modelo de prever uma determinada classe de interesse. Nesse trabalho, ela mede a porcentagem de regiões de gás classificadas corretamente.

Assim com a sensibilidade, a especificidade mede a capacidade do modelo de prever com precisão a classe complementar. Nesse trabalho, ele mede a porcentagem de regiões de não gás que são classificadas corretamente. 
A acurácia representa a média dentre as classes de interesse. Nesse trabalho, ela mede a porcentagem de regiões que são classificadas corretamente como suas classes, sendo elas regiões de gás ou não.

Por fim, a métrica área abaixo da curva ROC (AUC) é derivada da curva ROC ("Receiver Operating Characteristic"). Assim para enter a AUC é necessário antes entender a curva ROC.

A curva ROC mostra a capacidade com que o modelo criado pode distinguir entre duas classes. Assim, na tentativa de simplificar a análise da ROC, a AUC nada mais é que uma maneira de resumir a curva ROC em um único valor.

Além disso, a AUC também mede a qualidade das previsões do modelo, independentemente do limiar de classificação. 


\section{4 \\ Metodologia Proposta}

Os dados sísmicos possibilitam serem tratado de duas formas diferentes, sendo elas: tratar os dados sísmicos como sinal (1D) traço a traço ou utilizar as seções sísmicas como imagens (2D). Essa seção discute inicialmente a escolha por se trabalhar no sinal sísmico em detrimento da imagem. Em seguida aborda as etapas da solução proposta e conclui com o modelo de redes criado.

\section{1}

\section{Dimensionalidade da Solução Proposta}

A grande maioria dos algoritmos de detecção de feições (horizontes, falhas, etc.) em imagens sísmicas são baseados em redes convolucionais profundas, CNNs do inglês Convolutional Neural Network. O treinamento supervisionado dessas redes segue o padrão convencional das redes neurais. Essas redes são treinadas em imagens com as feições de interesse já marcadas. No linguajar da área o conjunto de valores ao redor de cada pixel é uma amostra e, quando sabemos a classificação de uma amostra, dizemos que ela é rotulada. As redes neurais profundas são treinadas com milhares de amostras rotuladas. O treinamento determina os coeficientes da rede e, depois de treinadas, espera-se que as CNNs detectem nas novas imagens sísmicas os pixels que estejam representando a feição para a qual a rede foi treinada a detectar.

O treinamento de CNNs em imagens sísmicas apresentam dois problemas importantes: número insuficiente de dados rotulados e ruídos. As redes profundas requerem centenas de milhares de amostras rotuladas e isso é difícil de se obter em sísmica. Os reservatórios de gás encontrados no norte do Brasil, por exemplo, são bastantes finos, dificultando a obtenção de muitas amostras que possam ser rotuladas como de gás. Uma janela de 31x31 pixels, centrada num pixel do reservatório de gás muito provavelmente tem as bordas fora dele. Isto porque temos poucos pixels na vertical. Com isso fica muito difícil gerar o número necessário de amostras para treinar a rede. $\mathrm{O}$ fato de a sísmica terrestre ser muito ruidosa também atrapalha muito.

Uma maneira de se produzir mais amostras com a mesma quantidade de imagens sísmicas rotuladas com reservatórios de gás consiste em reduzir o tamanho da vizinhança do pixel rotulado como gás. Com amostras menores uma mesma região produz mais amostras. A proposta apresentada aqui consiste em não trabalharmos com regiões, mas com traços. Ao reduzir a dimensionalidade, o número de pixels da amostra reduz bastante. Uma janela de 31x31 em torno de um pixel numa imagem, 
por exemplo, tem 961 valores. Olhando apenas o traço que contém aquela amostra a janela tem apenas 31 pixels.

A escolha de trabalhar no domínio do traço também pode ter outra explicação. Todo processo de migração dos dados pré-empilhados busca criar um traço que tem um sentido específico. O traço sísmico representa a resposta de uma onda unidimensional descendo na subsuperfície e refletindo nas interfaces entre camadas de impedância acústica diferentes. Esse modelo, chamado de modelo convolucional, é naturalmente unidimensional.

O modelo do traço unidimensional se assemelha a outros sinais como o do som e da voz. Se observarmos a literatura vamos ver que as redes neurais bemsucedidas para esses modelos não são as convolucionais, mas sim as recorrentes. Diferentemente das redes convolucionais, as redes recorrentes implicitamente reconhecem um conceito de série temporal e a classificação de uma amostra depende das amostras que vieram antes dela. Isto também ocorre no modelo de uma onda refletindo em camadas de da subsuperfície e no modelo convolucional correspondente. Por isso, optamos por trabalhar com o traço e não com a imagem sísmica.

\section{2}

\section{Etapas da Solução}

O método proposto possui as três etapas clássicas de visão computacional: (a) pré-processamento, (b) treinamento, e (c) detecção. O pré-processamento neste caso consiste em limpeza e normalização dos dados. O treinamento neste caso é o convencional nas redes neurais recorrentes e objetiva a determinação dos parâmetros da rede. A detecção objetiva atribuir a cada voxel do levantamento sísmico uma probabilidade dele conter ou não gás.

Os valores máximos das amplitudes das ondas sísmicas nos dados empilhados dependem do processo de migração e são, de certa forma, arbitrários e podem variar de um levantamento para outro. Para uniformizar as amostras de diversos treinamentos é interessante colocá-las numa mesma escala, por exemplo variando no intervalo $[-1,+1]$, sem alterar os voxels de valor zero.

Num levantamento sísmico também é comum termos voxels cujo valor não foi medido mas que aparecem no meio de outros valores calculados. Frequentemente encontramos nos arquivos segy esses voxels com o valor correspondente a máxima representação computacional do tipo de dado que armazena a amplitude.

No pré-processamento a limpeza consiste na retirada das áreas que não interessam no levantamento e na eliminação dos ruídos de aquisição que estejam nas áreas que vamos considerar. A limpeza no nosso caso consiste em definir uma região de interesse, ROI, (Region of Interest), que é a área do levantamento sísmico que pode ter acumulo de gás. A retirada dos ruídos é uma etapa que depende 
do levantamento sísmico. Já a normalização se faz dividindo todos o valores de amplitude pela valor máximo dos módulos das amplitudes.

$\mathrm{O}$ treinamento também se faz de forma usual. O método proposto, de todas as imagens (inlines ou crosslines) que contém marcação de gás, separa 15\% delas para teste, $15 \%$ para validação e $70 \%$ para treinamento. Ou seja, o treinamento, validação e teste são feitos em amostras de seções distintas.

Finalmente, o detalhe importante dessa nossa proposta é o processo de janelamento.

\section{3 \\ Processo de Janelamento}

O algoritmo consiste em extrair todos os traços sísmicos para cada seção sísmica, crossline ou inline. A partir do conjunto de traços extraídos é aplicado o processamento de janelamento descrito no algoritmo 1.

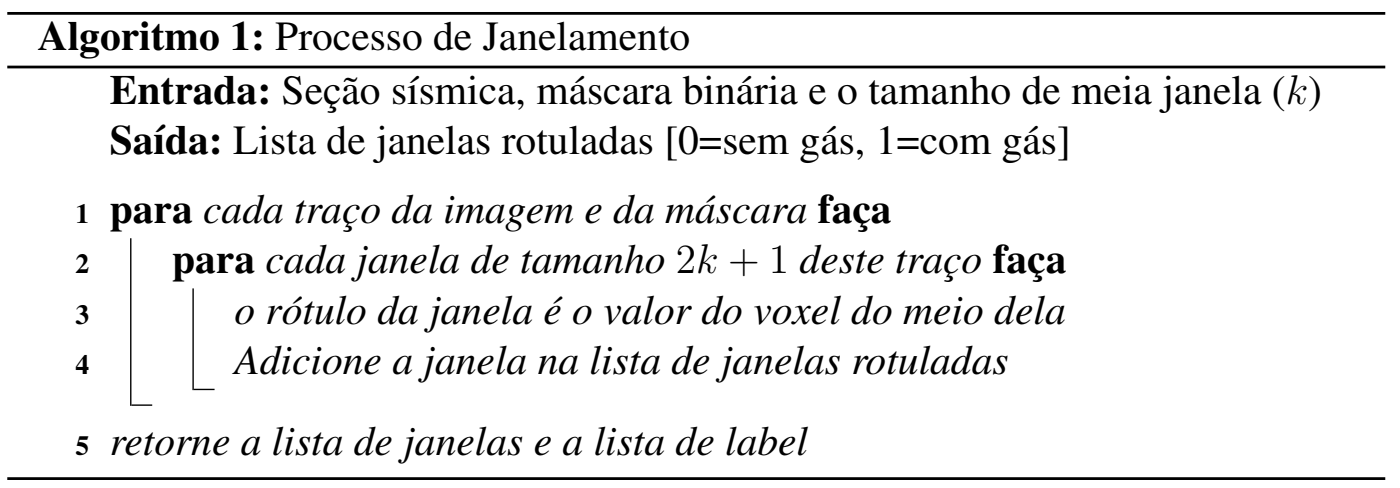

O tamanho da janela influencia na quantidade de informação que ela carrega para alimentar o modelo de redes neurais. Já a quantidade de sobreposições entre elas definem o tamanho da base de dados finais. Neste processo proposto sugerimos um valor de $k$ próximo de 20 e o passo de 1 . Ou seja, o centro das janelas varia de voxel em voxel no traço. A Figura 4.1 exemplifica o processo de janelamento em um traço sísmico. 


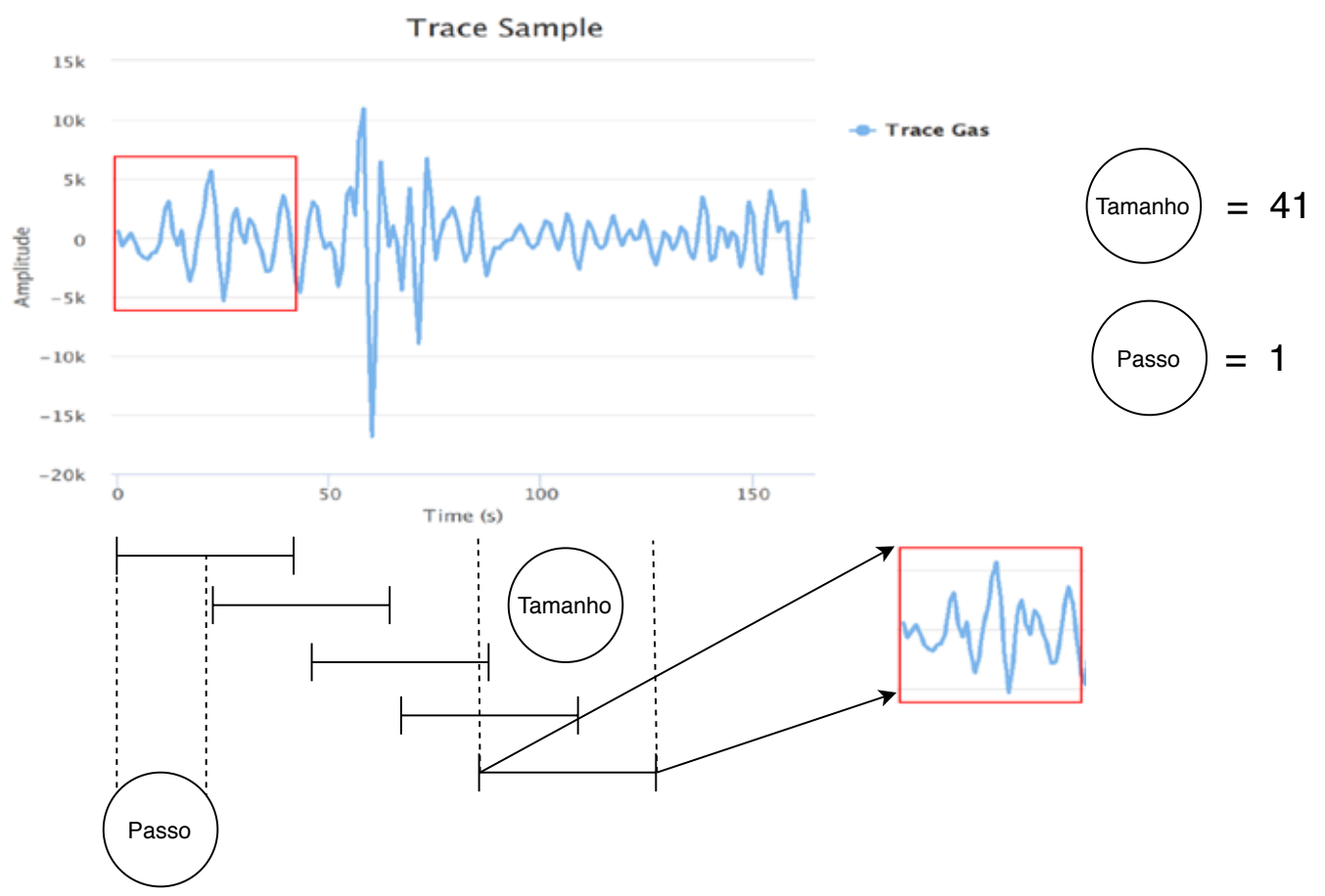

Figura 4.1: Processo de Janelamento.

\section{4}

\section{Arquitetura LSTM Proposta}

Um das principais vantagens em se utilizar uma rede neural LSTM é que ela permite que uma memória de entradas anteriores persista no estado interno da rede e, portanto, influencie na saída de novas entradas da rede (44). Sendo assim, amostras anteriores do traço sísmico afetarão a classificação de outras. Neste sentido, o modelo pode identificar o efeito do gás físico no sinal sísmico antes da chegada da assinatura do gás no traço sísmico. Logo, essa abordagem de carregar a informação contribuí na criação de um melhor modelo de classificação, alinhando a identificação do DHI nos dados sísmicos.

Além disso, uma abordagem 1D tem o benefício de produzir uma quantidade maior de amostras para treinar e analisar o modelo. Diversos trabalhos mostram que para o treinamento efetivo de uma rede neural profunda, geralmente é necessária um volume de dados expressivo, em uma abordagem 2D ou 3D, usando a imagem sísmica, não poderia satisfazer a quantidade de tais amostras.

Para esse trabalho foram utilizadas quatro células LSTM para processar as janelas sísmicas. Essas células são responsáveis na extração das informações presentes nas janelas e assim possibilitando identificar os fenômenos presentes nas duas classes.

Por fim, o modelo apresenta dois neurônios de saída, empregando a função softmax, que determina a probabilidade da janela avaliada pertencer a uma das duas classes. A Figura 4.2 ilustra a rede descrita. 


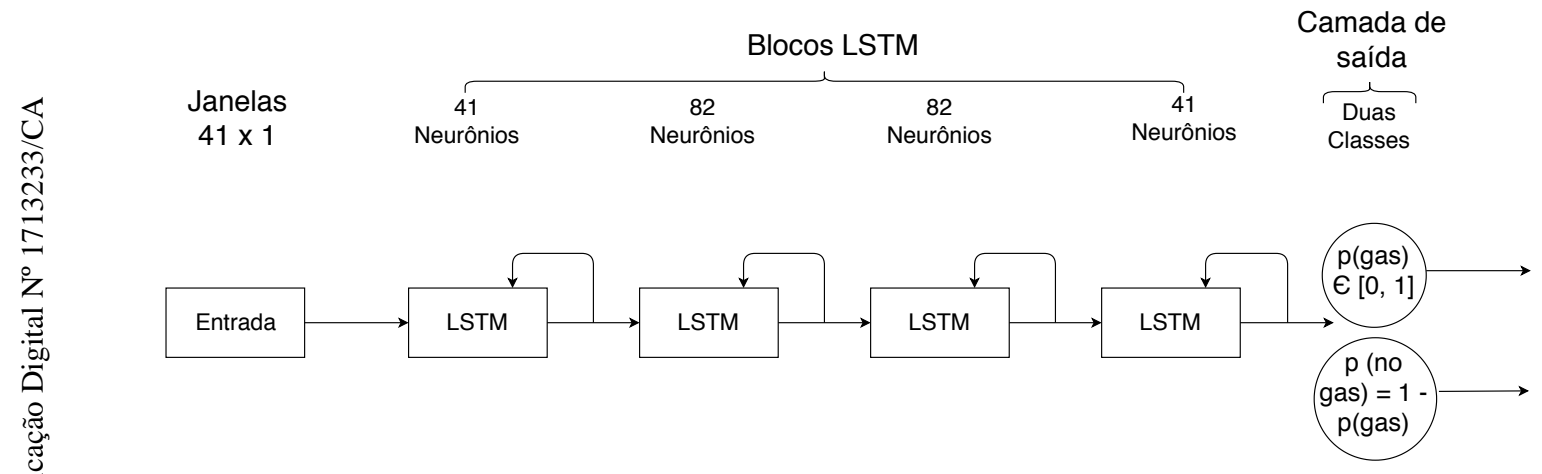

Figura 4.2: Arquitetura LSTM proposta. 


\section{Resultados}

A metodologia proposta nesta dissertação foi desenvolvida como uma prova de conceito para um projeto de pesquisa patrocinado por uma empresa de energia. Os levantamentos sísmicos utilizados na prova de conceito são adquiridos de campos terrestres brasileiros desta empresa. A prova de conceito produziu excelentes resultados, mas como o contrato de patrocínio da empresa ainda está em discussão, a conclusão da dissertação está sendo feita com base em dados públicos. Apesar das duas sísmicas serem muito diferentes a metodologia proposta se mostrou eficaz para ambos os levantamentos.

Nesta dissertação, no artigo que foi submetido com base nela, e na análise de uma patente que a PUC-Rio está avaliando, utilizamos apenas os dados públicos.

\section{1}

\section{Implementação}

Para a implementação da metodologia proposta foi utilizado a linguagem open source de script python versão 3.6. Dentre as rotinas implementadas destacamse: o leitor de segy, para a leitura das sísmicas, as rotinas de extração de traços, criação das máscaras de marcação e realização do processo de janelamento. Já a implementação do modelo de rede LSTM foi escolhido a utilização da biblioteca frontend Keras versão 2.2.4 (45) em conjunto com o TensorFlow como backend versão 1.12.0 (46).

O Keras é uma API de redes neurais de alto nível, escrita em Python e capaz de rodar em uma camada acima do TensorFlow, CNTK ou Theano. Foi desenvolvido com foco em permitir realizar experimentos de forma rápida. Já o TensorFlow é uma plataforma de código aberto para aprendizado de máquina. Ele possui um ecossistema abrangente e flexível de ferramentas, bibliotecas e recursos que permite que os pesquisadores promovam o estado-da-arte em aprendizado de máquina e que os desenvolvedores criem e implementem facilmente aplicativos baseados em ML. A seguir segue o trecho que descreve a implementação do modelo LSTM proposto.

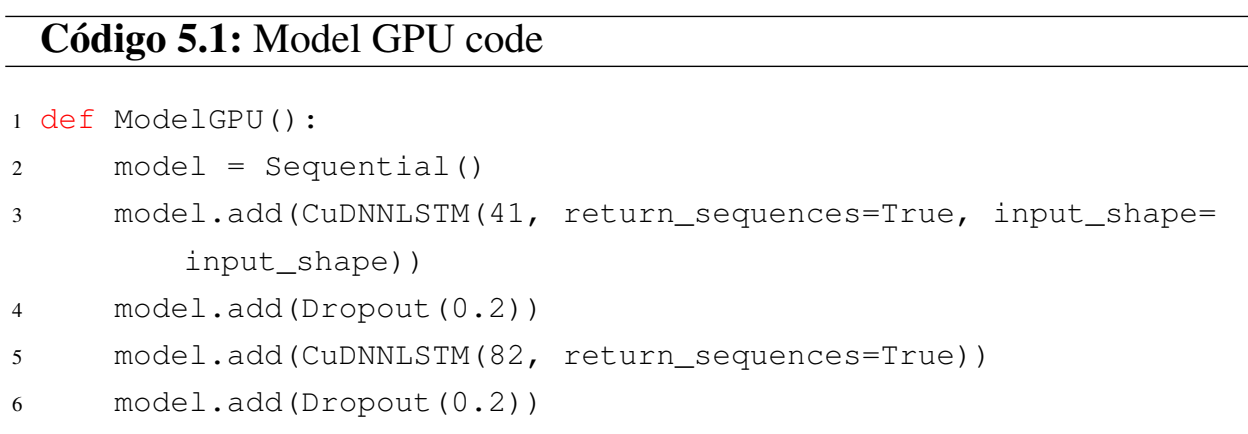




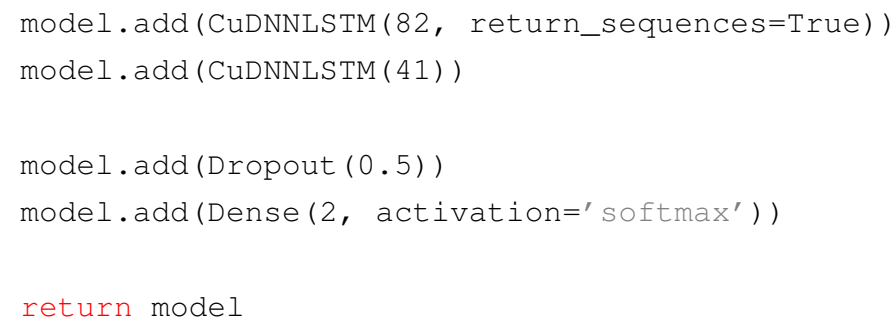

O primeiro comando presente na função é o Sequential, que corresponde ao construtor do modelo de rede neural. Em seguida, são inseridas as camadas de recorrência com o uso do comando CuDNNLSTM. Esse comando indica para a biblioteca que o usuário deseja que a recorrência seja feita em termos de uma, ou mais, GPU(s). Ao fim, e entre, as camadas de recorrência foi inserido o termo de Dropout. De forma simplificada, esse termo contribui para evitar o overfitting do modelo em questão durante o treinamento. Por fim, o comando Dense corresponde as camadas totalmente conectadas (fully-connected), também denomindas MLP.

\section{2}

\section{F3-Block 3D}

Os dados sísmicos utilizados para corroborar a metodologia proposta são os levantamentos sísmicos 3D públicos da Netherlands Offshore F3-Block(16), que estão disponíveis no Open Sismic Repository dGB Earth Sciences (1987), mantido pela dGB Earth Sciences. O conjunto de dados consistiu em $384 \mathrm{~km}^{2}$ de dados migrados em tempo sísmico 3D, com 651 linhas em inline e 951 linhas crossline, um intervalo de tempo de $1848 \mathrm{~ms}$, uma taxa de amostragem de $4 \mathrm{~ms}$ e um tamanho de caixa de $25 \mathrm{~m}$. A pesquisa está localizada na costa do Mar do Norte, na costa da Netherlands. Ao conduzir o sísmico 3D original, o repositório também fornece versões filtradas dos dados, cubos de impedância acústica (AI), alguns atributos sísmicos já computados, quatro poços (F02-1, F03-1, F03-4, F06-1) com marcadores e registros geofísicos, juntamente com oito correspondentes horizonte sísmico.

Para a localização manual das regiões de gás e seus possíveis indicadores, utilizamos não apenas o cubo disponível, mas também as outras informações acessíveis fornecidas. Juntamente com os dados sísmicos originais, os cubos de impedância e os registros de poços geofísicos tiveram papéis significativos na rotulagem da entrada de rede. A entrada de especialistas é essencial para as etapas apropriadas de treinamento e validação do algoritmo de deep learning e avaliação da metodologia.

No entanto, o cubo AI não apresenta informações para todo o registro sísmico (Figura 5.1 (b)), e a concentração primária de indicadores de gás é quase restrita perto dos estratos sigmoidais. Nesse sentido, as imagens sísmicas foram cortadas 
para uma região de interesse (ROI) (Figura 5.1), impedindo a possível imputação de dados ruidosos e rótulos de gases enganosos, aumentando assim a qualidade do treinamento da rede neural.

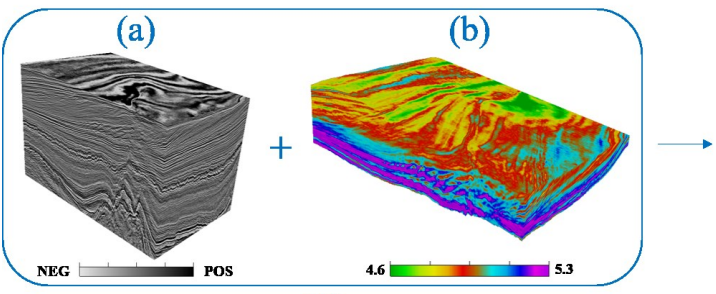

(1)

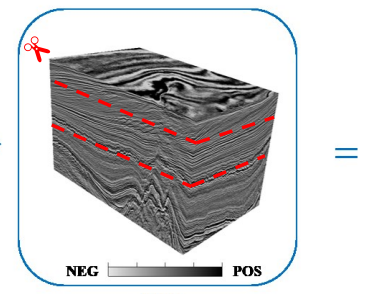

(2)

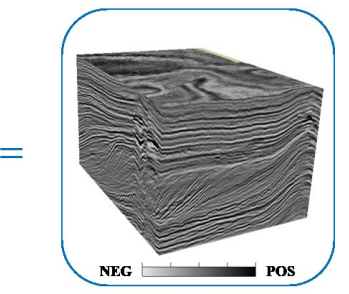

(3)

Figura 5.1: ROI processo de recorte: 1 - Dado disponível (a) Cubo Sísmico F3 (b) Cubo de impedância; 2 - Área selecionada e recorte; 3 - ROI do cubo.

\section{3}

\section{Descrição da Base de Dados}

O conjunto de dados foi composto por 691 imagens sísmicas, incluindo linhas crossline e inline, divididas em três partes: treinamento, teste e validação. Para os conjuntos de dados de teste e validação, 200 imagens sísmicas foram escolhidas aleatoriamente. Em relação ao conjunto de dados de treinamento, foram utilizadas 491 imagens.

Como a base original é consideravelmente desbalanceada, ou seja, a quantidade de janelas consideradas contendo gás são consideravelmente pequenas se comparadas às regiões de não gás, torna-se extremamente difícil para que o modelo consiga diferenciar bem as duas classes caso fosse utilizado todas as janelas consideradas de não gás. Assim, uma forma de contornar este problema, para o conjunto de dados de treinamento, foi selecionar todos os traços, de uma determinada imagem sísmica, contendo amostras de gás e selecionar aleatoriamente mais $20 \%$ de traços contendo amostras de não gás para a mesma imagem. Já para as bases de validação e teste foram utilizadas todas as janelas retiradas das imagens. As escolhas das janelas seguiram o seguinte critério: caso a janela possuísse metade de seu valor como gás ela é considerada uma janela de gás, caso ao contrário de não gás. Assim a distribuição das bases, com relação a número de janelas foi: 
Tabela 5.1: Número de Janelas por Base de Dados

\begin{tabular}{lll} 
Base & Regiões de Gás & Regiões de Não Gás \\
\hline Treino & 1.154 .242 & 5.060 .840 \\
Validação & 237.393 & 9.695 .007 \\
Teste (Inline) & 139.401 & 6.712 .839 \\
Teste (Crossline) & 55.540 & 3.024 .620
\end{tabular}

\subsection{1}

\section{Treinamento e Teste}

As janelas retiradas para as bases de treinamento e validação foram utilizadas para procurar as melhores configurações do modelo proposto. Para isso, foram realizadas diversas sessões de treinamento para comparar várias configurações com diferentes hiper-parâmetros. Ao final de cada treinamento, os modelos gerados tiveram seus pesos armazenados. Os resultados obtidos, na base de validação, de cada modelo foram comparados e o modelo que obteve os melhores resultados foi escolhido. A Tabela 5.2 a seguir mostra as métricas de validação obtidas aplicando o melhor modelo para o método.

Tabela 5.2: Métricas da Base de Validação

\begin{tabular}{lllll} 
Base & Acurácia (\%) & Sensibilidade (\%) & Especificidade (\%) & AUC (\%) \\
\hline Validação & 96.92 & 97.41 & 96.90 & 98.73
\end{tabular}

Uma vez encontrada a melhor configuração do modelo de rede, ele pode ser usado para classificar as janelas de teste. A Tabela 5.3 mostra os resultados obtidos pela aplicação do modelo na base de teste para Inlines e Crosslines.

Tabela 5.3: Métricas da Base de Teste

\begin{tabular}{lllll} 
Base & Acurácia (\%) & Sensibilidade (\%) & Especificidade (\%) & AUC (\%) \\
\hline Teste (Inline) & 97.28 & 98.60 & 97.25 & 99.47 \\
Teste (Crossline) & 96.92 & 95.07 & 96.95 & 98.94
\end{tabular}

\section{4}

\section{Comentários}

As métricas apresentadas pela Tabela 5.3 mostram a eficiência alcançada pelo algoritmo proposto. Através deles, é possível notar que o alto valor de sensibilidade 
e especificidade, aproximadamente $95 \%$ e $97 \%$, respectivamente, indicam que o modelo tem sucesso prevendo as regiões de acumulação de gás com baixa taxa de falsos positivos (previsões incorretas de gás pelo modelo). Além disso, a medida da AUC, com quase 99\%, indica que o algoritmo proposto foi capaz de diferenciar bem as duas classes.

Como mencionado no capítulo 4, o algoritmo de janelamento necessita que o usuário informe o tamanho da janela, assim como o passo de extração, para extração das janelas. Foram testadas diferentes tamanhos de janelas diferentes, e por fim, foi escolhido janelas com quarenta amostras de comprimento de janela com sobreposição de uma amostra de cada janela. $O$ tamanho da janela 40 x 1 possibilita que as janelas sejam grandes o suficiente para carregar informações significativas e também capturar informações úteis das regiões vizinhas. O que contribui para auxiliar o modelo de rede neural a diferenciar melhor as duas classes de interesse.

Os hiper-parâmetros do modelo foram escolhidos empiricamente com base nos resultados encontrados pelo treinamento. Nessa configuração as camadas de recorrência foram responsáveis por encontrar a sequência que representa a assinatura de gás.

Por fim, o tempo computacional gasto. Neste trabalho, como foram realizadas muitas sessões de treinamento para encontrar a melhor configuração para o modelo, o gasto computacional pode ser considerado elevado, uma vez que para cada sessão de treinamento era consumido em média quatro horas. Para contornar essa situação foi necessário utilizar um hardware mais poderoso. Assim, para os treinamentos, foi utilizado uma máquina com uma GPU NVIDIA GTX 1070 para acelerar a geração dos resultados. Por outro lado, após a conclusão da fase de treinamento, a classificação de todas as janelas de uma imagem sísmicas é feita em poucos segundos, mesmo usando somente a CPU. O tempo gasto para treino assim como os resultados para a base de teste são mostrados na Tabela 5.4.

Tabela 5.4: Tempo Computacional em GPU

\begin{tabular}{lll} 
Base & Tamanho (GB) & Tempo \\
\hline Treino (1 época) & 5.2 & 0h 22m 56s \\
Teste (Inline) & 2.2 & 0h 15m 34s \\
Teste (Crossline) & 1.0 & 0h 7m 24s \\
Validação & 3.2 & 0h 22m 4s
\end{tabular}

\section{5}




\section{Visualização}

A Figura 5.2, Figura 5.3, Figura 5.4 e Figura 5.5 apresentam os resultados gráficos do método proposto e os respectivos mapas de calor. Os resultados visuais corroboram a indicação das métricas apresentadas acima.

Uma breve analise das imagens mostra que quase todas as marcações de gás (marcações vermelhas) foram preditas pelo modelo (marcações verdes), com algumas restrições de contorno causadas pela sobreposição das janelas.

A presença de falsos positivos, indicada pelas métricas, concentra-se principalmente nos estratos clinoform e nas camadas superiores. No entanto, o mapa de calor, que representa a distribuição de probabilidade da janela, evidencia que a maioria dos falsos positivos tem baixa confiança de predição. Portanto, a maioria deles pode ser desconsiderada como possível DHI-gás.
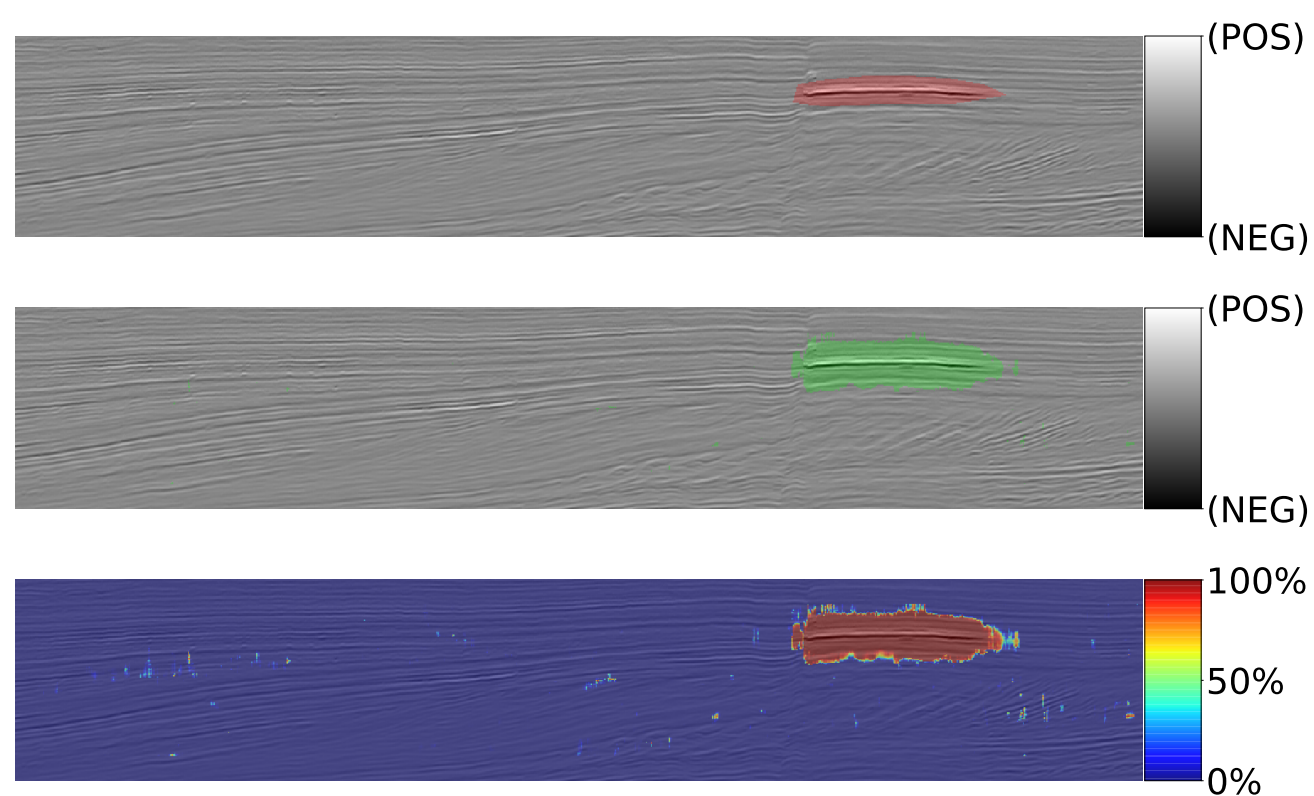

Figura 5.2: Resultado da predição do modelo para inline 249. 


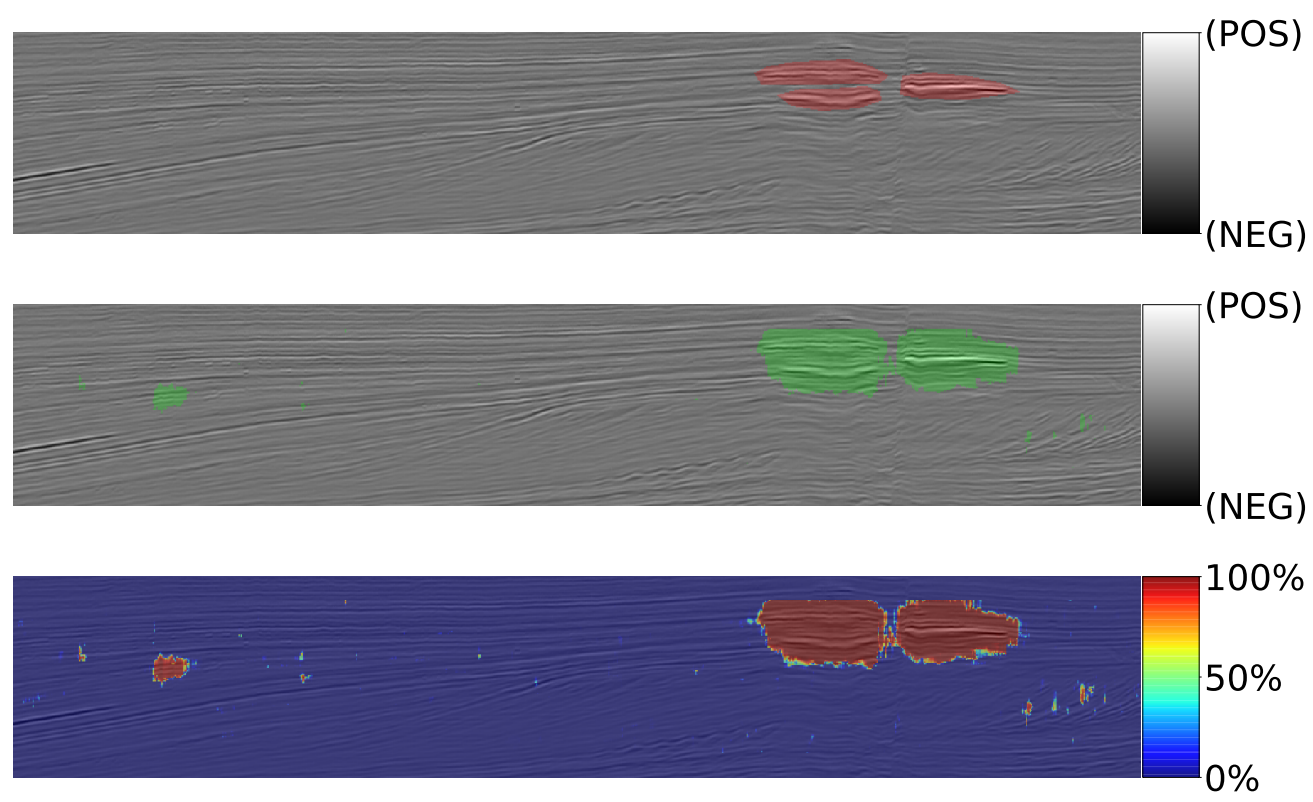

Figura 5.3: Resultado da predição do modelo para inline 120.
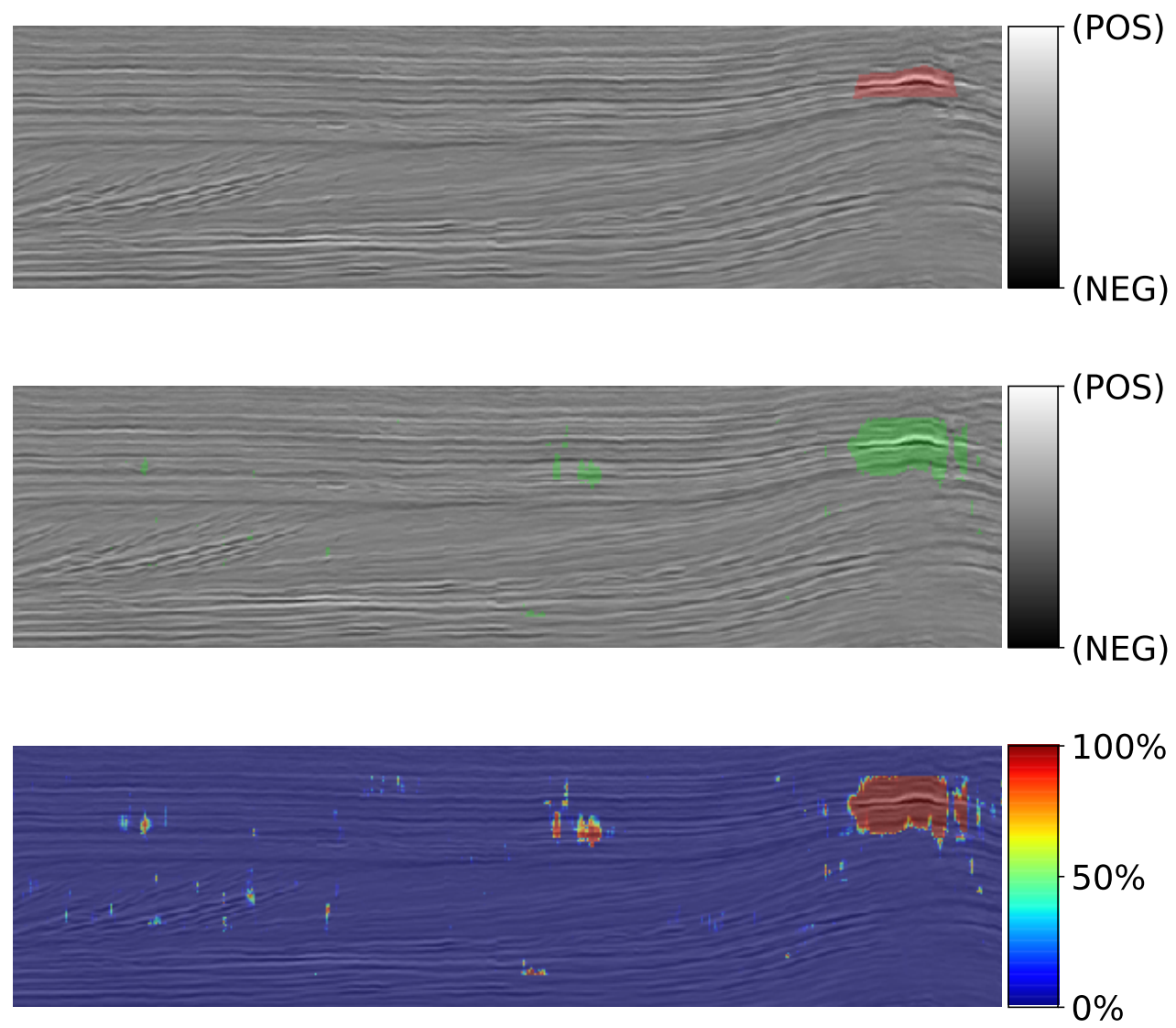

Figura 5.4: Resultado da predição do modelo para crossline 1156. 

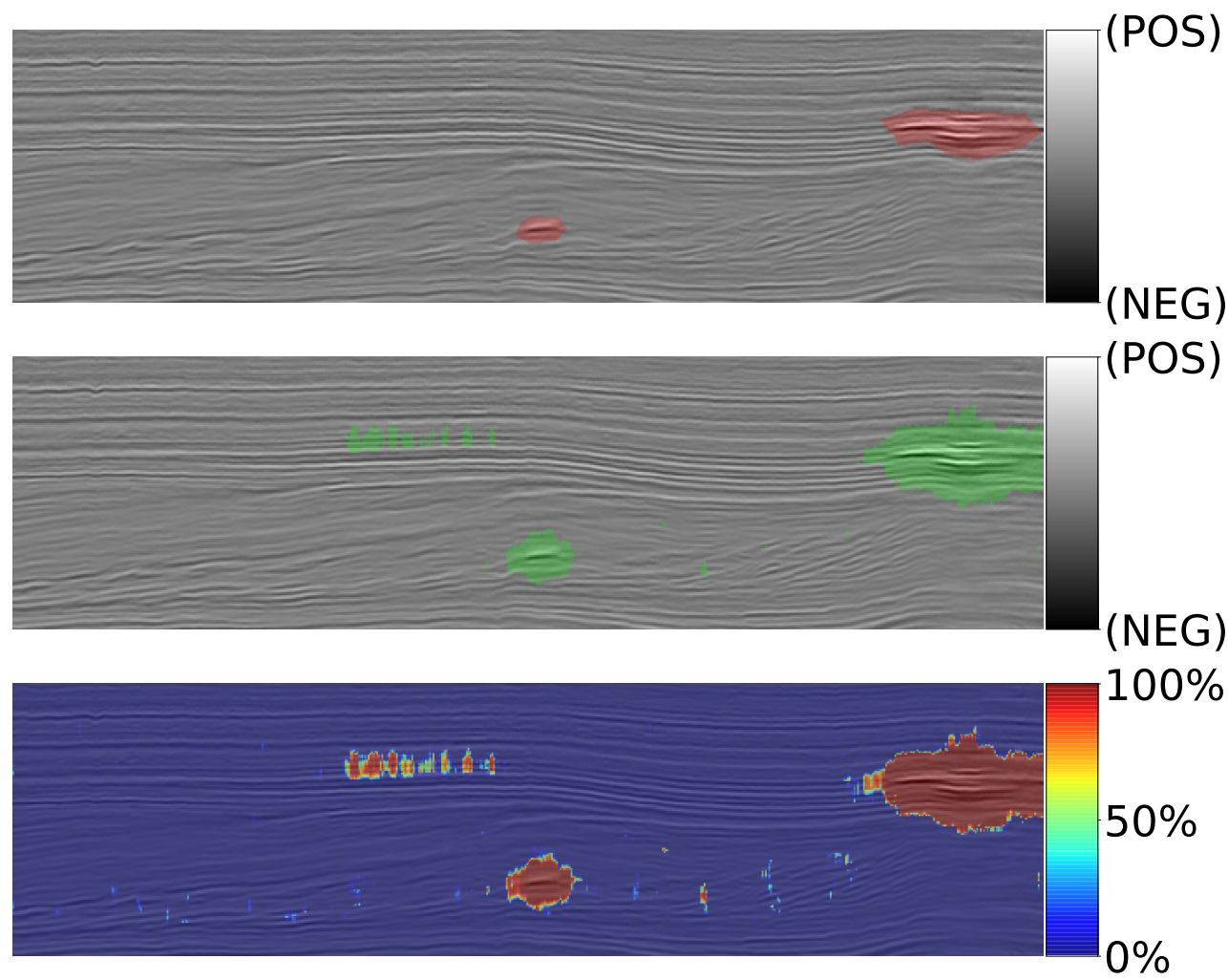

Figura 5.5: Resultado da predição do modelo para crossline 846. 


\section{6 \\ Conclusões e Trabalhos Futuros}

O trabalho apresenta uma nova metodologia para encontrar assinaturas de gás em traços sísmicos, produzindo bons DHIs em imagens sísmicas. Para validar o método, usamos um conjunto de dados sísmicos abertos reais para detectar as regiões de gás. Métricas quantitativas e mapas de calor confirmam a qualidade dos resultados.

O método usa os traços sísmicos, uma abordagem 1D, em vez da imagem sísmica, abordagem 2D ou 3D. Com essa estratégia 1D, conseguimos produzir mais amostras rotuladas com a mesma quantidade de dados interpretados. Além disso, a aplicação do LSTM no traço sísmico deu a vantagem de realizar a análise sempre com conhecimento prévio de amostras examinadas anteriormente. Portanto, foi possível para o modelo entender os possíveis efeitos do gás nos traços sísmicos antes que o acúmulo de gás real seja analisado.

O método provou ser robusto, com métricas consideravelmente altas e resultados gráficos sólidos. Assim, é possível concluir que o método proposto pode auxiliar efetivamente os especialistas a tarefa de detectar possíveis assinaturas do DHI em imagens sísmicas. Assim, otimizando o procedimento de interpretação sísmica, reduzindo custos e tempo de uma fase exploratória de O\&G.

Como principal contribuição do trabalho destacamos a criação de uma metodologia inovadora para detecção de regiões com assinaturas de gás em traços sísmicos. Tal abordagem pode se tornar uma poderosa ferramenta quando se trata de imagens muito ruidosas, como é o caso de sísmica terrestre, nas quais abordagens mais tradicionais 2D tornam-se muito difíceis ou até mesmo inviáveis. Outro ponto importante é que a proposta se baseia no traço empilhado podendo tratar igualmente levantamentos sísmicos 2D e 3D. Mais ainda, a metodologia foi testada numa base privada de imagens sísmicas terrestres $2 \mathrm{D}$ e bastante ruidosa com resultados similares aos mostrados aqui neste trabalho.

Mesmo com resultados satisfatórios, acreditamos que na estratégia proposta ainda existem algumas evoluções que podem alcançar melhores resultados. Como trabalho futuro poderia ser feita uma análise para tornar a arquitetura proposta profunda. Outra contribuição seria permitir que o modelo receba mais de um sinal como entrada e assim possibilitando que o modelo tenha mais informação para novas entradas. Uma outra possível evolução, para área de redes neurais, é uma extensão da camada LSTM para avaliar o traço em 3D. Por fim, poderia ser usado técnicas para encontrar os hiper-parâmetros do modelo automaticamente, como algoritmos de otimização evolucionários, entre outros. 


\section{Referências bibliográficas}

[1] MORTON-THOMPSON, D.; WOODS, A. M. ; OTHERS. Development geology reference manual: AAPG methods in exploration series, no. 10. Número 10. AAPG, 1993. 1

[2] KEAREY, P.; BROOKS, M. ; HILL, I.. An introduction to geophysical exploration. John Wiley \& Sons, 2013. 1

[3] COLLOBERT, R.; WESTON, J.. A unified architecture for natural language processing: Deep neural networks with multitask learning. In: PROCEEDINGS OF THE 25TH INTERNATIONAL CONFERENCE ON MACHINE LEARNING, p. 160-167. ACM, 2008. 1

[4] KRIZHEVSKY, A.; SUTSKEVER, I. ; HINTON, G. E.. Imagenet classification with deep convolutional neural networks. In: ADVANCES IN NEURAL INFORMATION PROCESSING SYSTEMS, p. 1097-1105, 2012. 1

[5] ROY, S.; KIRAL-KORNEK, I. ; HARRER, S.. Deep learning enabled automatic abnormal eeg identification. In: 2018 40TH ANNUAL INTERNATIONAL CONFERENCE OF THE IEEE ENGINEERING IN MEDICINE AND BIOLOGY SOCIETY (EMBC), p. 2756-2759. IEEE, 2018. 1

[6] POCHET, A.. Modeling of Geobodies: AI for seismic fault detection and all-quadrilateral mesh generation. PhD thesis, Pontifícia Universidade Católica do Rio de Janeiro, 2019. 1

[7] TINGDAHL, K. M.; DE ROOIJ, M.. Semi-automatic detection of faults in 3d seismic data. Geophysical prospecting, 53(4):533-542, 2005. 2.1

[8] DI, H.; SHAFIQ, M. A. ; ALREGIB, G.. Seismic-fault detection based on multiattribute support vector machine analysis. In: SEG TECHNICAL PROGRAM EXPANDED ABSTRACTS 2017, p. 2039-2044. Society of Exploration Geophysicists, 2017. 2.1

[9] GUITTON, A.; WANG, H. ; TRAINOR-GUITTON, W.. Statistical imaging of faults in 3d seismic volumes using a machine learning approach. In: SEG TECHNICAL PROGRAM EXPANDED ABSTRACTS 2017, p. 2045-2049. Society of Exploration Geophysicists, 2017. 2.1 
[10] ZHANG, C.; FROGNER, C.; ARAYA-POLO, M. ; HOHL, D.. Machinelearning based automated fault detection in seismic traces. In: $76 \mathrm{TH}$ EAGE CONFERENCE AND EXHIBITION 2014, 2014. 2.1

[11] ARAYA-POLO, M.; DAHLKE, T.; FROGNER, C.; ZHANG, C.; POGGIO, T. ; HOHL, D.. Automated fault detection without seismic processing. The Leading Edge, 36(3):208-214, 2017. 2.1

[12] WANG, Z.; DI, H.; SHAFIQ, M. A.; ALAUDAH, Y. ; ALREGIB, G.. Successful leveraging of image processing and machine learning in seismic structural interpretation: A review. The Leading Edge, 37(6):451-461, 2018. 2.1

[13] HUANG, L.; DONG, X. ; CLEE, T. E.. A scalable deep learning platform for identifying geologic features from seismic attributes. The Leading Edge, 36(3):249-256, 2017. 2.1

[14] DI, H.; WANG, Z. ; ALREGIB, G.. Seismic fault detection from poststack amplitude by convolutional neural networks. In: 80TH EAGE CONFERENCE AND EXHIBITION 2018, 2018. 2.1

[15] POCHET, A.; DINIZ, P. H.; LOPES, H. ; GATTASS, M.. Seismic fault detection using convolutional neural networks trained on synthetic poststacked amplitude maps. IEEE Geoscience and Remote Sensing Letters, 16(3):352-356, 2019. 2.1

[16] Osr, dgb earth sciences. project netherlands offshore f3 block. https://terranubis.com/datainfo/Netherlands_ offshore_F3_Block_-_Complete. Accessed: 2018-05-11. 5.2

[17] CHEVITARESE, D.; SZWARCMAN, D.; E SILVA, R. G. ; BRAZIL, E. V.. Deep learning applied to seismic facies classification: A methodology for training. In: SAINT PETERSBURG 2018, 2018. 2.1

[18] CHEVITARESE, D.; SZWARCMAN, D.; DA GAMA, S. R. ; BRAZIL, E. V.. Transfer learning applied to seismic images classification. AAPG Annual and Exhibition, 2018. 2.1

[19] ZHAO, T.. Seismic facies classification using different deep convolutional neural networks. In: SEG TECHNICAL PROGRAM EXPANDED ABSTRACTS 2018, p. 2046-2050. Society of Exploration Geophysicists, 2018. 2.1 
[20] XIONG, W.; JI, X.; MA, Y.; WANG, Y.; ALBINHASSAN, N. M.; ALI, M. N. ; LUO, Y.. Seismic fault detection with convolutional neural network. Geophysics, 83(5):097-0103, 2018. 2.1

[22] DI, H.; WANG, Z. ; ALREGIB, G.. Deep convolutional neural networks for seismic salt-body delineation. In: AAPG ANNUAL CONVENTION AND EXHIBITION, 2018. 2.1

[23] HOPFIELD, J. J.. Neural networks and physical systems with emergent collective computational abilities. Proceedings of the national academy of sciences, 79(8):2554-2558, 1982. 2.2

[24] BENGIO, Y.; SIMARD, P.; FRASCONI, P. ; OTHERS. Learning longterm dependencies with gradient descent is difficult. IEEE transactions on neural networks, 5(2):157-166, 1994. 2.2

[25] HOCHREITER, S.; BENGIO, Y.; FRASCONI, P.; SCHMIDHUBER, J. ; OTHERS. Gradient flow in recurrent nets: the difficulty of learning long-term dependencies, 2001. 3.1.1

[26] HOCHREITER, S.; SCHMIDHUBER, J.. Long short-term memory. Neural computation, 9(8):1735-1780, 1997. 2.2

[27] GERS, F. A.; SCHMIDHUBER, J. ; CUMMINS, F.. Learning to forget: Continual prediction with Istm. 1999. 2.2

[28] GREFF, K.; SRIVASTAVA, R. K.; KOUTNÍK, J.; STEUNEBRINK, B. R. ; SCHMIDHUBER, J.. Lstm: A search space odyssey. IEEE transactions on neural networks and learning systems, 28(10):2222-2232, 2016. 2.2

[29] GRAVES, A.; LIWICKI, M.; FERNÁNDEZ, S.; BERTOLAMI, R.; BUNKE, H. ; SCHMIDHUBER, J.. A novel connectionist system for unconstrained handwriting recognition. IEEE transactions on pattern analysis and machine intelligence, 31(5):855-868, 2008. 2.2

[30] GRAVES, A.; MOHAMED, A.-R. ; HINTON, G.. Speech recognition with deep recurrent neural networks. In: 2013 IEEE INTERNATIONAL CONFERENCE ON ACOUSTICS, SPEECH AND SIGNAL PROCESSING, p. 6645-6649. IEEE, 2013. 2.2

[31] Apple is bringing the ai revolution to your iphone. 
apple-bringing-ai-revolution-iphone/. Accessed: 201606-16. 2.2

[32] The neural networks behind google voice transcription. http: //googleresearch.blogspot.co.at/2015/08/ the-neural-networks-behind-google-voice.html. Accessed: 2017-06-27. 2.2

[33] Google voice search: faster and more accurate. http: //googleresearch.blogspot.co.uk/2015/09/ google-voice-search-faster-and-more.html. Accessed: 2017-06-27. 2.2

[34] Chat smarter with allo. http: / / googleresearch.blogspot. co. at/2016/05/chat-smarter-with-allo.html. Accessed: 201706-27. 2.2

[35] WU, Y.; SCHUSTER, M.; CHEN, Z.; LE, Q. V.; NOROUZI, M.; MACHEREY, W.; KRIKUN, M.; CAO, Y.; GAO, Q.; MACHEREY, K. ; OTHERS. Google's neural machine translation system: Bridging the gap between human and machine translation. arXiv preprint arXiv:1609.08144, 2016. 2.2

[36] Apple's machines can learn too. https://www. theinformation . com/apples-machines-can-learn-too. Accessed: 2017-06-27. 2.2

[37] iphone, ai and big data: Here's how apple plans to protect your privacy I zdnet. http://www.zdnet.com/article/ ai-big-data-and-the-iphone-heres-how-apple-plans-to-protect-your-p Accessed: 2017-06-27. 2.2

[38] An infusion of ai makes google translate more powerful than ever I wired. https://www.wired.com/2016/09/ google-claims-ai-breakthrough-machine-translation/. Accessed: 2017-06-27. 2.2

[39] ios 10: Siri now works in third-party apps, comes with extra ai features. http://bgr.com/2016/06/13/ ios-10-siri-third-party-apps/. Accessed: 2017-06-27. 2.2

[40] Bringing the magic of amazon ai and alexa to apps on aws. http://www.allthingsdistributed.com/2016/11/ 
amazon-ai-and-alexa-for-all-aws-apps.html. Accessed: 2017-06-27. 2.2

[41] Microsoft's speech recognition system is now as good as a human. http://newatlas.com/ microsoft-speech-recognition-equals-humans/50999.

Accessed: 2017-08-27. 2.2

[42] Sigkdd. http: //www.kdd.org/. Accessed: 2017-06-27. 2.2

[43] GERHARDT, B.. Aspectos da Visualização Volumétrica de dados Sísmicos. PhD thesis, Pontifícia Universidade Católica do Rio de Janeiro, 1998. A

[44] GOODFELlOW, I.; BENGIO, Y. ; COURVILLE, A.. Deep learning. MIT press, 2016. 4.4

[45] Keras documentation. https: //keras.io/. Accessed: 2019-05-11. 5.1

[46] Tensorflow documentation. https: //www.tensorflow.org/. Accessed: 2019-05-11. 5.1 


\section{A \\ O Dado Sísmico}

Este apêndice busca introduzir os conceitos de sísmica necessários para que um leitor de outras áreas possa compreender a dissertação sem ter que recorrer a outras fontes. Ela não é original e se baseia no trabalho de Gerhardt (43).

A sísmica de reflexão é uma das principais técnicas de construção de imagens da subsuperfície para a prospecção, procura de reservatórios de hidrocarbonetos. De forma geral os acúmulos de óleo e gás são encontrados em rochas sedimentares. Uma rocha sedimentar é formada a partir da acumulação, diagênese e solidificação de sedimentos, podendo ser de origem clástica, química ou orgânica. À medida que os sedimentos vão se empilhando em uma bacia sedimentar, o aumento de pressão ativa os processos físicos, químicos e biológicos de formação de rochas sedimentares que compõem a diagênese, tais como: compactação, cimentação, recristalização, hidratação, lixiviação, ação de bactérias, etc. Garantida uma temperatura adequada, os sedimentos orgânicos podem começar a gerar hidrocarbonetos, sendo então denominados rochas geradoras. Os hidrocarbonetos fluem através de meios permeáveis segundo o fenômeno da migração. Por terem densidades menores que a da água, são por ela deslocados ao encontrar uma via de escape. Se nenhuma trapa é encontrada, acabam por escapar pela superfície da terra. Entretanto, se durante a migração existir uma combinação entre uma rocha capeadora impermeável e um meio poroso, os hidrocarbonetos podem ser trapeados e acumulados para formar um reservatório. Meios porosos típicos são arenitos e calcários, enquanto os selantes mais comuns são camadas de rochas sedimentares não-permeáveis, como os folhelhos.

A prospecção de hidrocarbonetos pode ser feita por métodos diretos, ou seja, com a perfuração dos poços, que apresentam um alto custo. Apesar de serem necessários para efetivamente identificar as acumulações, os poços fornecem apenas informações pontuais. Outra forma é aplicar métodos indiretos, que são mais baratos e fornecem informações de área ou volumétricas, embora necessitem interpretações. Dentre os métodos indiretos mais comuns estão a gravimetria, a magnetometria e a sísmica de refração e de reflexão.

A sísmica de reflexão é o método indireto mais empregado e o que fornece imagens mais precisas da subsuperfície. Seus princípios físicos 
estão associados com a reflexão de ondas elásticas nas interfaces entre diferentes meios de propagação. É empregada uma fonte sísmica artificial em contato com a superfície para emitir ondas através das camadas rochosas da terra. Na grande maioria dos casos são usadas ondas do tipo $\mathrm{P}$ (pressure - pressão), que apresentam o deslocamento de partículas paralelo à direção de avanço da onda em meios isotrópicos. A frente de ondas se propaga com uma velocidade entre 300 a $7000 \mathrm{~m} / \mathrm{s}$, dependendo do tipo de material, e de forma geral aumenta com a profundidade. Uma interface entre duas litologias encontrada pela frente de ondas ao longo de sua trajetória pode refletir parte da energia de volta à superfície, onde é então registrada por receptores dispostos em arranjos afastados das fontes. $\mathrm{O}$ tempo de percurso e a amplitude do campo de ondas são as duas únicas grandezas medidas pelo método.

De forma simplificada, para que a energia seja refletida nas interfaces é necessário que exista um contraste de impedância acústica, definida como o produto da velocidade de propagação pela densidade do meio. Este contraste é denominado coeficiente de reflexão ou refletividade, que para a incidência normal de uma onda plana em uma interface é dado por:

$$
R_{n+1}=\frac{Z_{n+1}-Z_{n}}{Z_{n+1}+Z_{n}}
$$

onde $\mathrm{n}$ é o índice da camada geológica na coluna estratigráfica e:

$$
Z_{i}=\rho_{i} V_{i}
$$

sendo $\rho_{i}$ a densidade e $V_{i}$ a velocidade do som na camada $i$.

A equação A-1 é obtida da solução das condições de contorno da equação que expressa tensão e deslocamento nas interfaces. Os valores que $R_{n}$ pode assumir variam entre $-1.0 \mathrm{e}+1.0$, situações em que há reflexão total da energia incidente. Note-se que um coeficiente de reflexão negativo implica em inversão de fase, ou seja, uma compressão retorna como tração. Quando as impedâncias são iguais a refletividade é nula e a interface não é vista pelos métodos sísmicos. $A$ expressão (A-1) não é mais válida quando a incidência deixa de ser normal. Neste caso a energia incidente em uma interface é dividida em componentes de pressão $(P)$ e cisalhamento ( $\mathrm{S}$ - shear), conforme determinado pelas equações de Knott ou Zoeppritz (Sheriff, 1991).

A relação (A-1) expressa uma diferença que é essencialmente a derivada da distribuição espacial da impedância acústica. Em uma situação ideal, em que o meio de propagação é totalmente homogêneo e o experimento físico é isento de ruídos, não são registradas quaisquer informações 
entre as interfaces. Portanto, os dados sísmicos são observações mais relacionadas às diferenças entre os materiais do que a estes próprios.

O conjunto de todos os coeficientes de reflexão presentes em uma coluna estratigráfica é denominado função refletividade. Nela os coeficientes de reflexão são representados como funções delta de Dirac nas posições correspondentes às interfaces a que estão associados. Como mostra a figura a seguir.
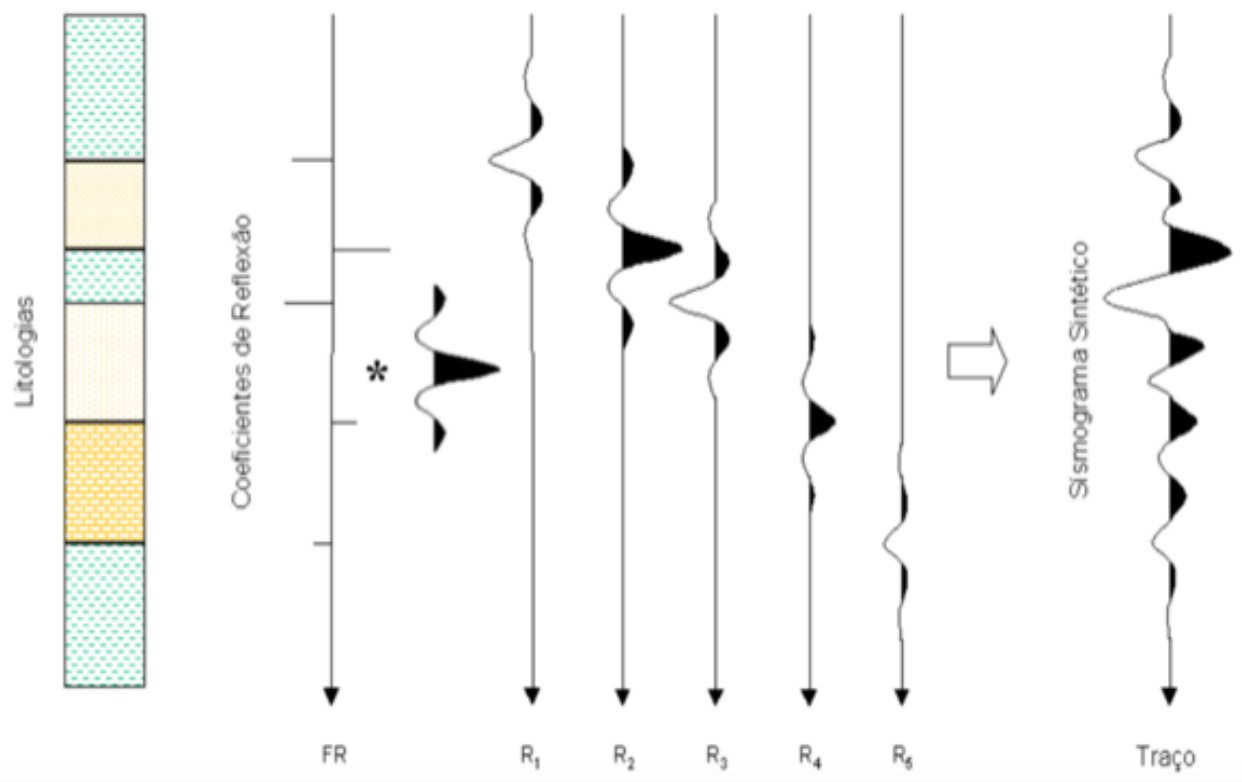

Figura A.1: Processo de formação de um traço sísmico através da convolução do pulso emitido pela fonte com a função refletividade (FR).

O traço sísmico é obtido da convolução da função refletividade com o pulso emitido pela fonte. O processo está ilustrado na Figura A.1 utilizando uma coluna estratigráfica simples e um pulso sísmico sintético do tipo Ricker. Em cada interface entre duas litologias a forma do pulso é multiplicada pelo coeficiente de reflexão e mapeada nesta posição; o conjunto de todos os resultados é então somado para formar o traço. Note-se que algumas amplitudes resultantes não guardam correspondência direta com os coeficientes que as geraram e outra aparecem onde nem mesmo existem interfaces. Este efeito é resultante do uso de um pulso com um conteúdo limitado de frequências.

O uso de um pulso sísmico com um conteúdo limitado de frequências implica em um limite de resolução do método. Em sísmica, resolução pode ser definida como a capacidade de separar dois eventos muito próximos com base em algum critério. Em termos de resolução vertical, dois critérios bastante usados são $\lambda / 4$ ou $\lambda / 8$ onde $\lambda$ é o comprimento de onda dominante do pulso. Dessa forma, a menor espessura possível de resol- 
ver com o método sísmico depende da velocidade média e do conteúdo de frequências do sinal. No limite, onde todas as frequências estão presentes, a resolução é total, já que o pulso é a própria função delta de Dirac. $\mathrm{Na}$ prática, as frequências associadas às reflexões variam na faixa de 30 a 60 $\mathrm{Hz}$. Considerando uma velocidade média de $2000 \mathrm{~m} / \mathrm{s}$, a menor espessura distinguível pela sísmica é da ordem de $5 \mathrm{~m}$ segundo o critério de $\lambda / 8$

O modelo da Figura A.1 está referenciado em profundidade. Entretanto, o método sísmico mede o tempo de propagação que o pulso leva para refletir nas interfaces até ser registrado nos receptores (tempo duplo de propagação - ida e volta do pulso). Portanto, o processo de convolução é realizado à medida que o pulso encontra as interfaces ao avançar em tempo, sendo o tempo de ocorrência de cada coeficiente de reflexão determinado pela velocidade de propagação das ondas elásticas dentro de cada litologia (velocidade intervalar).

Existem diversos caminhos possíveis da fonte até o receptor com o mesmo tempo de percurso. Um de particular interesse são as múltiplas, que resultam do fenômeno de reverberação de energia entre uma ou mais camadas. A aparência de uma múltipla nos registros é semelhante a uma reflexão primária. Entretanto, a múltipla leva mais tempo do que uma reflexão primária da mesma interface para atingir a superfície, dando a falsa impressão de ser uma reflexão de uma interface mais profunda. Um problema sério relacionado à qualidade dos dados sísmicos é a alta quantidade de ruídos, definidos como quaisquer energias registradas que não sejam o sinal de interesse. Existem diversas fontes de ruídos. A mais evidente são as condições não controladas de aquisição de campo, que geram o ruído ambiental ou aleatório. Os ruídos gerados pelas fontes sísmicas estão associados a diversas ondas que se propagam próximas à superfície, sendo alinhados nos registros e por isso denominados ruídos coerentes. O nível de ruídos é particularmente alto na maioria dos dados terrestres, cuja qualidade é em geral baixa devido à grande distorção sofrida pelo pulso sísmico nas camadas intemperizadas próximas da superfície. Essas camadas representam uma zona de baixa velocidade de propagação que se estende desde a superfície até dezenas ou centenas de metros de profundidade, em geral coincidindo com o lençol freático. As velocidades de propagação dentro desta zona variam entre 300 e $1500 \mathrm{~m} / \mathrm{s}$. Os retardos provocados por estas baixas velocidades, associados às variações de topografia da superfície e da base da camada de intemperismo, acabam por degradar a continuidade espacial dos refletores.

O meio de propagação, a terra, é uma grande fonte de distorção, 
apresentando o comportamento típico de um filtro corta-altas. A absorção seletiva de frequências resulta em um alongamento do pulso sísmico, com uma consequente perda de resolução. $O$ pulso que efetivamente se propaga pelo subsolo também está sujeito ao decaimento de amplitude devido ao espalhamento geométrico (diminuição da densidade de energia). Estes problemas são particularmente críticos para reflexões com longos tempos de percurso. Dessa forma, a amplitude dos sinais tende a decrescer com o tempo, enquanto que o ruído aleatório persiste e eventualmente domina.

\section{A.1}

\section{Aquisição de Dados}

Existem diversas técnicas de aquisição sísmica. Este trabalho se limita aos procedimentos envolvidos no método de aquisição CMP (Common Mid-Point). Uma ilustração do esquema de aquisição bidimensional em terra e no mar é apresentada na Figura A.2. No caso da aquisição tridimensional são empregadas mais linhas de receptores em paralelo.

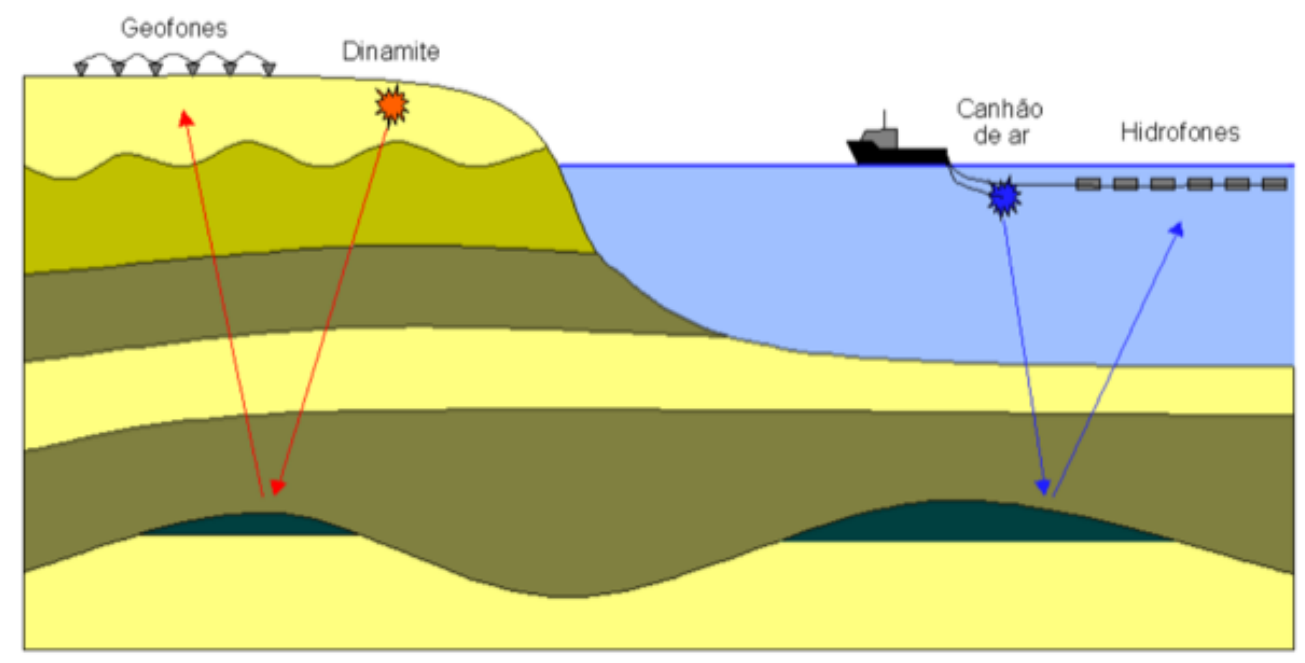

Figura A.2: Princípio da aquisição terrestre e marítima de dados sísmicos.

As fontes sísmicas convencionais podem ser explosões de dinamite, canhões pneumáticos de ar, vibradores possantes, etc. Os receptores são geofones, que medem a velocidade da passagem do pulso sísmico pelo terreno, ou hidrofones, que medem a variação de pressão por ele gerada na água. Ambos são transdutores que convertem as variações das ondas sísmicas em valores de tensão. Estes são genericamente denominados amplitudes sísmicas e variam de negativo a positivo, sendo armazenados como números em representação digital de ponto flutuante. Cada fonte 
é composta por um grupo de diversos elementos, distribuídos segundo um arranjo com o intuito de melhorar o acoplamento com o solo (no caso da aquisição terrestre) ou modelar um pulso desejado através de interferência (na aquisição marítima). Da mesma forma, cada estação de receptores é formada por um arranjo de diversos elementos, com o objetivo de discriminar os comprimentos de onda dos ruídos coerentes e atenuar o ruído ambiental em relação ao sinal. A cada fonte corresponde um grande número de receptores, podendo chegar facilmente a mil em levantamentos tridimensionais. Os receptores são conectados ao equipamento de controle e registro denominado sismógrafo, que executa a conversão analógicodigital dos valores de amplitude e armazena os dados em meio magnético. Em geral os dados são registrados entre quatro e oito segundos, com um intervalo de amostragem de dois milissegundos, o que pode gerar uma massa de dados de até $16 \mathrm{MB}$ por registro.

Após adquirir os dados em uma determinada posição de tiro, o dispositivo de registro (fontes e receptores) é movido para a posição seguinte e o processo é repetido até que a cobertura total da área seja atingida. Esta movimentação é feita segundo critérios (e.g., intervalo de tiros, receptores, número de canais (receptores) ativos por tiro, etc.) que determinam o custo do levantamento.

\section{A.2 \\ Processamento Sísmico}

O processamento sísmico compreende um conjunto de técnicas que atuam sobre os dados de modo a retirar efeitos indesejáveis e aumentar a relação sinal-ruído, visando facilitar a interpretação. Nesta Seção, apenas as três técnicas principais são discutidas de maneira sucinta. $\mathrm{Na}$ ordem comum de aplicação, são elas: (i) deconvolução, (ii) empilhamento e (iii) migração. Maiores detalhes podem ser encontrados em Yilmaz (1987)

\section{A.2.1 \\ Deconvolução}

O sinal ideal emitido pela fonte sísmica seria um delta de Dirac, i.e., um pulso com duração infinitesimal e amplitude infinita, que ao ser convolvido com a função refletividade resultaria nela própria. Entretanto, isso não é realizável fisicamente. Desta forma, o pulso resultante apenas aproxima de forma muito grosseira a função delta de Dirac. $O$ resultado desta aproximação pode ser visto na Figura A.1, em que foram geradas 
amplitudes que não estão diretamente relacionadas com interfaces nos seus tempos de registro correspondentes

A deconvolução é um processo que atua ao longo do eixo do tempo e visa remover o pulso sísmico básico, distorcido pelos efeitos de propagação e pelo instrumento de registro, dos dados sísmicos registrados e assim obter uma melhor aproximação da função refletividade. Esta meta é atingida pela compressão do pulso, modificando a sua forma para um delta de Dirac (spiking deconvolution) através de técnicas baseadas em filtros de Wiener. A deconvolução alarga o espectro dos dados, que passam a apresentar um conteúdo maior de frequências após a sua aplicação, resultando em um aumento de resolução temporal.

Geralmente é necessária uma filtragem após o processo, já que tanto o sinal quanto os ruídos de alta freqüência são amplificados. Outra forma de deconvolução visa a remoção das múltiplas presentes nos dados utilizando filtros preditivos (predictive deconvolution)

\section{A.2.2}

\section{Empilhamento}

O empilhamento (stacking) é um processo que responde por uma enorme compressão do volume total de dados adquiridos. Uma grande quantidade de traços sísmicos em um mesmo CMP é corrigida de NMO e empilhada (os traços são somados), resultando em um único traço que simula uma situação em que fonte e receptor são coincidentes, embora com uma melhor discriminação de ruído. O objetivo é atenuar efeitos aleatórios e eventos cuja dependência do afastamento seja diferente das reflexões primárias.

As reflexões inclinadas não resultam em um ponto comum de reflexão, e sim em uma área espalhada alinhada com o mergulho da interface. Nesses casos é normalmente aplicada uma correção denominada DMO (Dip Move-Out) antes do empilhamento. O DMO é o processo que corrige o efeito de espalhamento dos pontos de reflexão ao longo das superfícies inclinadas, transformando um CMP em um CRP (Common Reflection Point). Após a sua aplicação, eventos com diversas inclinações são empilhados com a mesma velocidade (Sheriff, 1991).

A correção dos efeitos da camada de intemperismo é feita logo antes do empilhamento a fim de garantir uma maior continuidade dos refletores ao longo dos afastamentos. Essa correção é dita estática por ser constante para todo o traço, convertendo as amplitudes para um modelo em que fontes e receptores são deslocados verticalmente para um plano de referência 
onde não existe material intemperizado.

\section{A.2.3 Migração}

A lei de Snell dita que o ângulo de incidência é igual ao de reflexão e que o ponto de reflexão nas interfaces está a meio caminho entre fonte e receptor se o refletor é horizontal. Quando as ondas são refletidas por horizontes inclinados ou quando existem variações laterais de velocidade, a reflexão registrada nos receptores não é mais proveniente do ponto médio. Como resultado, a informação sísmica é registrada em posições de superfície diferentes das suas equivalentes em subsuperfície, gerando uma falsa impressão das estruturas. Este efeito é corrigido pelo processo denominado migração. A migração recoloca os refletores na sua posição espacial correta e colapsa difrações, podendo assim ser entendida como um processo de deconvolução espacial que visa aumentar a resolução espacial.

A migração pode ser executada antes ou depois do empilhamento, sendo este último o caso mais comum. O processo pode empregar soluções numéricas do tipo diferenças finitas, continuação do campo de ondas, integração ao longo de curvas de difração ou equivalentes no domínio da frequência. Existem migrações especiais que produzem um novo volume ou seção já convertido para profundidade (migração em profundidade).

O produto final do processamento sísmico é uma seção ou volume que tenta aproximar uma imagem da subsuperfície, embora em tempo. Os milhares de traços presentes em uma seção ou volume são ajustados através das técnicas de processamento descritas acima. $O$ volume de dados produzido pelo processamento sísmico 3D representa os valores de amplitude para cada ponto $(x, y, z)$ que está posicionado nos nós de uma malha regular definida por inlines, ou linhas paralelas à direção preferencial de aquisição dos dados, e crosslines, perpendiculares àquelas e não levantadas diretamente no campo. Planos de z constante são denominados timeslices. Os valores $x$ e y representam as coordenadas geográficas, enquanto $z$ pode representar tempo ou profundidade. Os intervalos de amostragem típicos nos eixos x e y são da ordem de uma dúzia de metros, estando diretamente relacionados com os custos de aquisição, enquanto em z é frequente uma reamostragem para quatro a partir dos originais dois milissegundos. Quando z está referenciado em profundidade, o espaço entre amostras depende da técnica de conversão para profundidade empregada, embora seja tipicamente da ordem de alguns metros. Portanto, existe uma 
forte tendência a haver muito mais amostras em $z$ do que nos demais eixos. Um arranjo tridimensional $X_{i j k}$ é normalmente usado para armazenar as amostras, com os índices indicando suas posições na malha.

A Figura A.3 mostra como as seções sísmicas são estruturadas, em 2D e 3D. Cada traço, Figura A.3 (a), é mapeado por um mapa de cores e assim, dão origem as seções sísmicas, Figura A.3 (b). O cubo sísmico, Figura A.3 (c), por sua vez é constituído por várias seções sísmicas perfiladas.

a

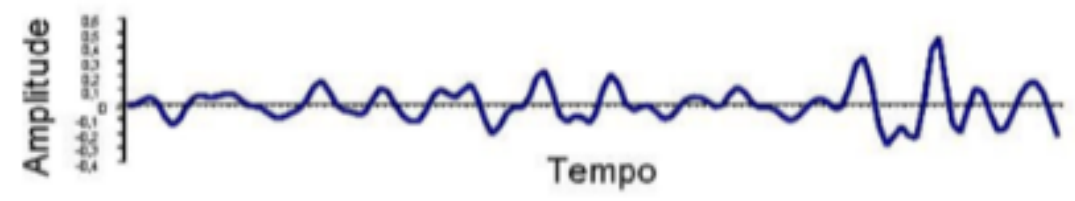

b c

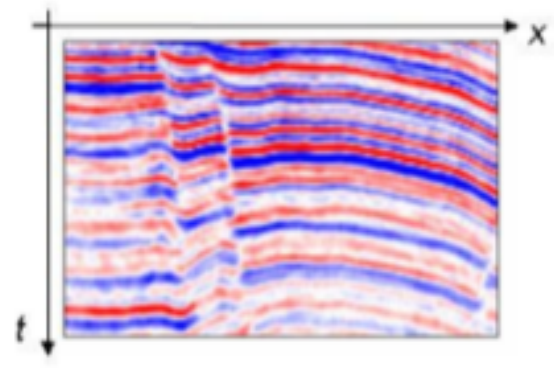

d
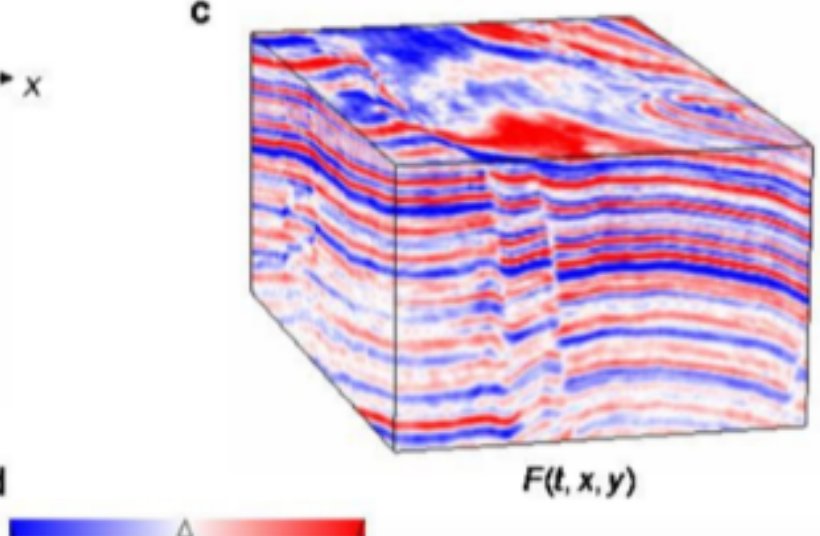

$F(t, x, y)$

Figura A.3: Criação dos dados sísmicos. 